\title{
Devaluation of fixed exchange rates: optimal strategy in the presence of speculation ${ }^{\star}$
}

\author{
Ivan Pastine \\ Economics Department, Bilkent University, 06533 Bilkent, Ankara, TURKEY \\ (e-mail: pastine@bilkent.edu.tr)
}

Received: May 17, 1999; revised version: June 2, 1999

Summary. This paper analyzes devaluations in a fixed exchange rate system by endogenizing both the speculation and devaluation decisions. It is shown that deterministic devaluation rules are generally sub-optimal for the central bank. In order to deter speculation the central bank introduces uncertainty into the timing of devaluation. The nature this mixed strategy is derived, as is the optimal strategy for speculators. The analysis allows an explanation of successful devaluations that are not precipitated by a speculative attacks, even under perfect capital mobility.

Keywords and Phrases: Speculative attack, Optimising balance-of-payments crises.

JEL Classification Number: F31, E58.

\section{Introduction}

A recurring problem with fixed exchange rate regimes is the need to periodically alter the exchange rate peg. This is a difficult problem for central banks because speculators will attempt to predict and exploit devaluations through their foreign currency purchases, creating the potential for an orderly devaluation to become a full-fledged exchange rate crisis. Moreover, foreign currency sold to speculators will either be lost or will have to be repurchased at the devalued exchange rate. In either case there is a strong incentive for the central bank to try to avoid a devaluation during a speculative attack by devaluing before the attack or, if it has sufficient reserves, riding out the attack and devaluing later.

\footnotetext{
* This paper is adapted from the third chapter of my Georgetown University Ph.D. dissertation. I would like to thank, without implicating, James Albrecht, Roland Bénabou, Susan Collins, Robert Cumby, Behzad Diba, F. William McElroy, Serge Moresi, Chul Park, Grace Pastine, Tuvana Pastine, and Susan Vroman.
} 
This paper analyzes this issue by endogenizing both the speculation and devaluation decisions. I show that deterministic devaluation rules are generally sub-optimal for the central bank. In order to deter speculation the central bank introduces uncertainty into the timing of devaluation. The nature this mixed strategy is derived, as is the optimal strategy for speculators.

The literature has extensively analyzed abandonments of fixed exchange rate systems. However, realignments in the fixed exchange rate regime have received relatively little analysis. In fact, realignments are more often observed than abandonments. For example, in their extensive study Eichengreen, Rose and Wyplosz find 101 devaluation or revaluations in the period 1959-93, as compared to 33 cases of fixed exchange rate abandonment.

Previous theoretical work examines realignments by analyzing only one side of the market. Either central bank behavior is taken as exogenous and the optimal speculator behavior is analyzed, or speculator behavior is taken as exogenous and optimal central bank behavior is analyzed. To my knowledge, this is the first paper that analyzes exchange rate realignments which endogenizes both central bank and speculator behavior.

Blanco and Garber (1986) started the line of research that analyzes realignments by studying speculator behavior, taking central bank strategies as exogenous. They extended the seminal work of Krugman (1979) and Salant and Henderson (1978) to incorporate devaluations rather than just fixed exchange rate abandonments. ${ }^{1}$ Flood and Marion (1997a) take speculator behavior as exogenous and analyze the central bank's problem. ${ }^{2}$ They show that in the absence of speculation the central bank's optimal realignment policy in an inflationary environment is given by an $(S, s)$. The central bank fixes the nominal exchange rate and offers to buy and sell foreign currency at that rate. As time goes by, however, the fixed exchange rate leads to a real appreciation. Eventually, the real exchange rate appreciates to $\mathrm{s}$, and the central bank devalues to the real exchange rate $S$, paying an adjustment cost to do so. The central bank then allows the real exchange rate to be eroded by inflation and then devalues again. ${ }^{3}$ As the authors point out, such investigations are only applicable to countries that are enforcing perfect capital controls.

In the absence of perfect capital controls speculators will naturally attempt to predict the timing of the devaluation and purchase foreign currency prior to it. Thus, the optimum strategy for speculators depends on the behavior of the central bank. Likewise, the optimum strategy for the central bank depends on the behavior of speculators. The central bank has an incentive to avoid speculative attacks. Rather than simply choosing a critical level of fundamentals at which to devalue the exchange rate and accepting a speculative attack, the monetary

\footnotetext{
${ }^{1}$ Surveys of the speculative attack literature are given by Agénor, Bhandari, and Flood (1992), Blackburn and Sola (1993), and Flood and Marion (1997b).

2 This approach is adapted from Sheshinski and Weiss (1977) where they show that optimal monopoly pricing in inflationary environments is given by an $(S, s)$ rule.

${ }^{3}$ See also Collins (1995) which takes a similar approach to inquire into what central banks are actually targeting.
} 
authority has an incentive to try to preempt an expected attack by devaluing before it occurs. Of course speculators will try to predict this preemptive devaluation and exploit it through their foreign currency purchases. In equilibrium, the central bank will deliberately introduce uncertainty about the timing and size of the devaluation. By making it difficult for speculators to predict the conditions under which it will change the exchange rate policy, the central bank can hope to avoid a speculative attack.

This incentive to introduce uncertainty into degree and timing of devaluations has not been previously analyzed. It implies that exchange rate uncertainty is in fact an important feature of fixed exchange rate regimes. Exchange rate uncertainty will be introduced endogenously, and deliberately by the monetary authorities in an attempt to avoid speculative attacks. Note, however, that one of the main arguments in favor of fixed exchange rates is that they may decrease the exchange rate uncertainty inherent in a floating exchange rate system. The results of this paper suggest that, in practice, the incentives of the monetary authorities may lead them to deliberately reintroduce much of this uncertainty in an attempt to avoid speculative attacks.

In this paper strategic interaction between many small foreign currency speculators and the central bank is analyzed as a Markov Perfect Nash equilibrium in an infinitely repeated game. This permits an investigation of optimal devaluation policy in the typical case of countries without perfect capital controls. ${ }^{4}$ The model has a parameter which captures some types of capital controls, and it is shown that with strong enough capital controls the equilibrium collapses to a deterministic $(S, s)$ rule for the central bank, as in Flood and Marion's (1997) work with perfect capital controls. However, with less onerous capital controls the equilibrium will be qualitatively different as the central bank actively tries to avoid speculative attacks.

Technically, the approach taken here is in the spirit of Bénabou (1989) who analyzes the pricing behavior of a monopolist in an inflationary environment facing consumers with unit demands, some of whom are able to store the good for one period. Conceptually, the extension of the durable goods monopolist's problem to the problem of a central bank facing speculators is quite clean (as Bénabou notes). However, there are technical complications. The assumption of unit demands allows Bénabou to pin down the upper price in his modified $(S, s)$ rule which is crucial in his proofs. One technical innovation of this paper is to derive the modified $(S, s)$ rule in a framework that is not restricted by unit demands. The speculators' demand for foreign currency is typically an increasing function of the perceived probability of a devaluation, as well as expected size of the devaluation. This generalization opens the opportunity for Bénabou's

\footnotetext{
4 This type of strategic interaction has been receiving increased attention in the literature on speculative attacks leading to abandonments of fixed exchange rate regimes. Examples include Andersen (1994), Cole and Kehoe (1996a,b), Davies and Vines (1995), Morris and Shin (1998), Obstfeld (1994, 1996), Ozkan and Sutherland (1994, 1995, 1998), Pastine (1998), and Velasco (1997). These papers find that many of the results of the earlier literature that did not incorporate strategic interaction are changed, either qualitatively or quantitatively, by strategic interaction between the central bank and speculators.
} 
approach to be applied to many more markets with adjustment costs, most of which have no analog of unit demands.

The next section provides a characterization of the game between many small speculators and the central bank. Section three then converts this specification into an equivalent game which is amenable to analysis, and derives the equilibrium. The intuition and implications of these results are presented in Section 4. Readers who are interested in getting an overview of the paper and its results without the mechanics of the proofs can read the framework in Section 2, the intuition in Section 4, and the implications in Section 5.

\section{Framework}

A central bank, with initial foreign currency reserves normalized to one, offers to buy and sell foreign currency at a nominal exchange rate s (domestic currency price of foreign currency). The infinitely lived central bank maximizes, in each period, the expected present value of its payoff function which is decreasing in the degree of exchange rate "misalignment": the difference between $\mathrm{s}$ and a target exchange rate $s^{*}$.

This target exchange rate depreciates at the rate $\pi \in(0, \infty)$, the inflation differential between the country and its trading partners. Therefore, if it does not devalue the central bank will have a constant nominal exchange rate and an increasing target nominal exchange rate. In order to achieve stationarity of the infinitely repeated game it is convenient to write this relationship as an appreciating real exchange rate $q$ and a constant target real exchange rate, $q^{*}$. The costs of misalignment are standard. A high real exchange rate results in costly imports for consumers and higher production costs due to the increased cost of imported inputs. A low real exchange rate results in decreased exports, reducing employment in the tradable goods sector. The target real exchange rate $q^{*}$ represents the policy maker's subjective balance between these costs, possibly due to the relative political power of the various interest groups in society. All players discount the future at rate $\delta \in(0,1)$ and the central bank must pay a menu $\operatorname{cost} \beta>0$ each time it alters the nominal exchange rate. $\beta$ represents unmodeled political and economic costs associated with a devaluation.

Each period a unit continuum of infinitely lived risk neutral speculators maximize the expected present value of their individual utilities. Each speculator has domestic currency balances of $m \in[s, \infty)$ available for speculative purchases of foreign currency. ${ }^{5}$ If wealth is held in foreign currency the speculator must pay a holding cost of $\alpha>0$. One useful interpretation of $\alpha$ is as a crude representation of capital controls. This interpretation will allow a direct comparison between

\footnotetext{
${ }^{5} m \geq s$ guarantees that full speculation will completely deplete the central bank's foreign currency reserves. For simplicity, $m$ is taken as state independent. This assumption is innocuous as long as $m \geq s$ for all possible states.
} 
the results of this paper and the previous literature which assumes perfect capital controls (arbitrarily high $\alpha$ ). ${ }^{6}$

At the beginning of every period the central bank observes the real exchange rate and level of foreign currency reserves and decides whether to alter the nominal exchange rate or to let the real exchange rate be eroded by inflation. Then, if it alters the nominal exchange rate, the central bank decides what new rate to set. At the end of each period the speculators observe the real exchange rate and the central bank's foreign currency reserves and choose a level of speculative foreign currency balances to carry into the next period.

Attention will be restricted to Markov perfect equilibria ${ }^{7}$ where strategies for all players depend only on payoff relevant state variables. Concentrating solely on state-space strategies reduces the number of equilibria from the potentially large set which arise when history dependent strategies are permitted. The resulting Markov perfect equilibria are still subgame perfect and, in general, more robust to renegotiation and to finite versus infinite specification of the game. Since the examination of purely state-space strategies does not permit the players to influence each other through reputation effects or to punish each other for past "misbehavior," the resulting equilibria can be thought of as the baseline equilibria from which the players may try to use reputations to deviate in a broader examination.

In period $n$ let $q(n)$ represent the real exchange rate and $f_{i}(n)$ and $f(n) \equiv$ $\int_{0}^{1} f_{i}(n) d i$ represent foreign currency balances held by speculator $i$ and all speculators respectively. All purchases are made with domestic currency so at the end of period $n$ speculator $i$ 's payoff is:

$$
G_{i}(n)=f_{i}(n-1) q(n)-f_{i}(n)[q(n)+\alpha]
$$

The first term represents the sale of foreign currency purchased in the previous period. The second term is the cost of current speculative purchases of foreign currency. Consider a devaluation which is expected in period $n ; q(n)$ is expected to be high relative to $q(n-1)$. In period $n-1$ speculator $i$ would purchase foreign currency and her period $n-1$ payoff would be lower by $[q(n-1)+\alpha]$ for each unit she purchased. However, in period $\mathrm{n}$ she would be able to sell it, gaining $q(n)$ in that period. If the difference between the expected $q(n)$ and $q(n-1)$ is great enough she will find speculation attractive and will purchase foreign currency in period $n-1$. From Eq. 1 the only payoff-relevant state variable for the choice of $f_{i}(n)$ is $q(n)$. Particularly, holdings of foreign currency brought forward from the previous period $f_{i}(n-1)$ are not payoff-relevant for the speculation decision.

At the end of period $n$ the central bank's payoff is:

$$
G_{C B}(n)=-\gamma\left|q(n)-q^{*}\right|+q(n)(f(n)-f(n-1))-\beta \Delta(q(n-1) / \theta, q(n))
$$

\footnotetext{
${ }^{6}$ In the absence of capital controls $\alpha$ could be interpreted as a (small) liquidity cost of holding foreign currency. Alternatively, it could be interpreted as the additional cost of monitoring foreign investment.

7 Due to Gertner (1985) and Maskin and Tirole (1987, 1988a,b).
} 
where $\theta \equiv 1+\pi$ and $\Delta(x, y) \equiv 0$ if $x=y$ and 1 otherwise. The first term represents the loss due to a deviation from the target exchange rate. ${ }^{8}$ The second term is the gain or loss due to purchases or sale of foreign currency. This is specified in much the same way as for the speculators so that speculators gains will be central bank loses. Notice that foreign currency reserves are a cost to the central bank. In the dynamic game they will prove useful in maintaining a fixed exchange rate but they are not desired for their own sake. ${ }^{9}$ Since $f(n)$ has not yet been chosen, the only payoff relevant state variables for the decision between $q(n)=q(n-1) / \theta$ or selecting a different $q(n)$, at cost $\beta$, are $f(n-1)$ and $q(n-1)$. If the central bank alters $s$, the only payoff relevant state variable for the choice of $q$ is $f(n-1)$. Markov strategies in this game can therefore be specified as follows.

For each Speculator: a mapping $/ i: q \in(0, \infty) \rightarrow / i \in[0, m / s]$, specifying her speculative purchases of foreign currency.

For the central bank: two mappings. One, $p:(q, f) \in(0, \infty) \times[0,1] \rightarrow \mu \in$ $[0,1]$, specifying its probability of altering the nominal exchange rate. And a

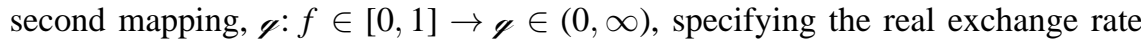
after the nominal exchange rate is altered.

\section{Characterization of the equilibrium}

\subsection{Dynamic optimization}

Define $\mathscr{T}_{S}\left(q, f_{i}\right)$ as speculator $i$ 's maximized expected present value of utility at her decision node (where $q$ is the current period's real exchange rate) and $\mathscr{T}_{S}\left(q, f, f_{i}\right)$ as her maximized expected present value of utility at the central bank's first decision node of the period (where $q$ is the previous period's real exchange rate). Assuming an equilibrium exists these can be written as:

$$
\begin{aligned}
\mathscr{T}_{S}\left(q, f, f_{i}\right) & =\mu(q, f) \mathscr{W}_{S}\left(q(f), f_{i}\right)+(1-\mu(q, f)) \mathscr{W}_{S}\left(q / \theta, f_{i}\right) \\
\mathscr{T}_{S}\left(q, f_{i}\right) & =f_{i} q+\max _{f_{i}^{\prime} \in[0, m / s]}\left\{-f_{i}^{\prime}[q+\alpha]+\delta \mathscr{T}_{S}\left(q, f(q), f_{i}^{\prime}\right)\right\}
\end{aligned}
$$

Defining $\tilde{\mu},(q) \equiv \mu(q, f(q))$ and $\tilde{q}(q) \equiv \mathscr{\ell}(\mathcal{f}(q)) \forall q$ and observing that speculator $i$ takes both $f(q)$ and $p(q, f)$ as given, at her decision nodes her value function is the solution to the Bellman equation:

\footnotetext{
${ }^{8}$ The additional assumption that $\gamma>\beta / q^{*}$ is sufficient to ensure that the central bank will prefer to devalue as some point rather than allow the real exchange rate to approach zero.

9 This is intended as a useful simplification capturing the aforementioned central bank incentive to avoid devaluations during a speculative attack. In reality central banks have reasons to care about foreign exchange stocks as well as flows. For example, assuming unsterilized currency sales, low foreign exchange reserves imply that the domestic money supply is low (since reserves were purchased with domestic currency) and therefore interest rates will be high. At the cost of additional complexity this could be included in the model but it would not change the basic results as long as the cost of low foreign exchange stocks is small enough that the central bank would prefer to wait out a one period speculative attack in order to devalue in its wake rather than during it. Since the costs of low foreign exchange stocks are proportional to the period length while the flow costs are not this is always the case for short period lengths.
} 


$$
\begin{gathered}
\mathscr{W}_{S}\left(q, f_{i}\right)=\max _{f_{i}^{\prime} \in[0, m / s]}\left\{f_{i} q-f_{i}^{\prime}[q+\alpha]+\delta \tilde{\mu}(q) \mathscr{T}_{S}\left(\tilde{q}(q), f_{i}^{\prime}\right)\right. \\
\left.+\delta(1-\tilde{\mu}(q)) \mathscr{W}_{S}\left(q / \theta, f_{i}^{\prime}\right)\right\}
\end{gathered}
$$

for all $q$ and her strategy $f_{i}$ is an associated optimal control.

For the central bank define $\mathscr{W}_{C B}(q, f)$ as the maximized expected present value of utility at its $p$ decision node where $q$ is the previous period's real exchange rate. Likewise, define $\mathscr{T}_{C B}(q, f)$ as the central bank's utility at the speculators decision node, where $q$ is the current period real exchange rate.

$$
\mathscr{T}_{C B}(q, f)=\max _{p \in[0,1]}\left\{p\left(\mathscr{T}_{C B}(\mathscr{y}(f), f)-\beta\right)+(1-p) \mathscr{T}_{C B}(q / \theta, f)\right\}
$$

and,

$$
\left.\mathscr{T}_{C B}(q, f)=q \mathscr{f}(q)-f\right)-\gamma\left|q-q^{*}\right|+\delta \mathscr{W}_{C B}(q, \mathscr{f}(q))
$$

Therefore, the central bank's value function at its $p$ decision nodes is the solution to the Bellman equation:

$$
\begin{aligned}
& \mathscr{T}_{C B}(q, f)=\max _{p \in[0,1]}\left\{p[\not / f)(f(\mathscr{y}(f))-f)-\gamma\left|\mathscr{\gamma}(f)-q^{*}\right|-\beta\right. \\
& \left.+\delta \mathscr{W}_{C B}(\mathscr{q}(f), \mathscr{f}(\mathscr{q}(f)))\right]+(1-p)[(q / \theta)(f(q / \theta)-f) \\
& \left.-\gamma\left|(q / \theta)-q^{*}\right|+\delta \mathscr{T}_{C B}(q / \theta, f(q / \theta))\right\}
\end{aligned}
$$

for all $q$ and his strategy $\rho$ is an associated optimal control. At the central bank's $q$ decision nodes its value function is the solution to:

$$
\mathscr{U}_{C B}(f)=\max _{q \in(0, \infty)}\left\{\mathscr{T}_{C B}(q, f)\right\}
$$

and his strategy $\%$ is an associated optimal control.

\subsection{Normalizations and definition of states}

In this problem there are two state variables, the central bank's reserves (equal to $1-f$ ) and the real exchange rate $q$. By a convenient normalization this can be reduced to a new problem with only one state variable per Bellman equation who's optimal controls coincide with the optimal controls for the original problem. From (4) and (7),

$$
\begin{aligned}
& \mathscr{T}_{S}\left(q, f_{i}\right)=\mathscr{T}_{S}(q, 0)+f_{i} q \\
& \mathscr{T}_{C B}(q, f)=\mathscr{T}_{C B}(q, 0)-f q
\end{aligned}
$$

Therefore define the normalized value functions,

$$
\begin{aligned}
\mathscr{W}(q) & \equiv \mathscr{T}_{S}(q, 0) \\
\mathscr{V}(q) & \equiv \mathscr{T}_{C B}(q, 0)
\end{aligned}
$$


for a representative speculator and the central bank respectively. Both value functions are measured at a decision node of speculators where speculators have zero holdings of foreign currency. From (5) $\mathscr{W}(q)$ satisfies,

$$
\begin{gathered}
\mathscr{W}(q)=\max _{f_{i}^{\prime} \in[0, m / s]}\left\{-f_{i}^{\prime}[q+\alpha]+\delta \tilde{\mu}(q)\left[\mathscr{W}(\tilde{q}(q))+f_{i}^{\prime} \tilde{q}(q)\right]\right. \\
\left.+\delta(1-\tilde{\mu}(q))\left[\mathscr{W}(q / \theta)+f_{i}^{\prime} q / \theta\right]\right\}
\end{gathered}
$$

and from (6) and (7) $\mathscr{T}(q)$ satisfies,

$$
\begin{gathered}
\mathscr{T}(q)=\max _{p \in[0,1]}\left\{q \mathscr{f}(q)-\gamma\left|q-q^{*}\right|+\delta p[\mathscr{T}(\tilde{q}(q))-\beta-\mathscr{f}(q) \tilde{q}(q)]\right. \\
+\delta(1-p)[\mathscr{V}(q / \theta)-\mathscr{f}(q) q / \theta]\}
\end{gathered}
$$

(10) can be rewritten as,

$$
\mathscr{W}(q)=\mathscr{W}_{S}\left(q, f_{i}\right)-f_{i} q
$$

Since $f_{i}$ is already fixed by the time the speculator is deciding on $f_{i}^{\prime},(14)$ is an equivalent way of specifying the speculator's dynamic programming problem and determining her optimal strategy $f$. By substituting (11) into (6) and noting that $f(q)$ is a constant by the time the central bank is making its devaluation decision, it is straightforward to verify that (15) is an equivalent way of specifying the central bank's dynamic programming problem and determining its optimal strategy $\mu$.

$\mathscr{\gamma}(f)$ is now the optimal control of,

$$
\mathscr{U b}_{C B}(f)=\max _{q \in(0, \infty)}\{\mathscr{T}(q)-f q\}
$$

Define,

$$
q_{0} \equiv \max _{f \in[0,1]} \not(f)
$$

Assume, for now, $q_{0} \in(0, \infty)$ and for any $t \in \mathbb{R}_{+}$define state $t$ as any period when the real exchange rate is $q_{t} \equiv q_{0} \theta^{-t}$. Now define: $V_{t} \equiv \mathscr{T}\left(q_{t}\right)$, $W_{t} \equiv \mathscr{W}\left(q_{t}\right), p_{t} \equiv \mu\left(q_{t}, f\left(q_{t}\right)\right), f_{i t} \equiv f_{i}\left(q_{t}\right)$, and $f_{t} \equiv \mathcal{f}\left(q_{t}\right)$. For notational convenience, define $q\left(f_{t}\right) \equiv \mathscr{\gamma}\left(f_{t}\right), V\left(f_{t}\right) \equiv \mathscr{V}\left(\mathscr{\varphi}\left(f_{t}\right)\right), W\left(f_{t}\right) \equiv \mathscr{W}\left(\mathscr{q}\left(f_{t}\right)\right), \mathfrak{F}$ as the set of functions mapping $\mathbb{R}_{+}$into $[0,1]$ and define $\mathfrak{F}^{-1}$ as the set of functions mapping $[0,1]$ into $\mathbb{R}$.

The normalized Bellman equation for a representative speculator is, therefore,

$$
W_{t}=\max _{f_{i} \in[0, m / s]}\left\{-f_{i}\left[q_{t}+\alpha\right]+\delta\left[p_{t}\left(W\left(f_{t}\right)+f_{i} q\left(f_{t}\right)\right)+\left(1-p_{t}\right)\left(W_{t+1}+f_{i} q_{t+1}\right)\right]\right\}
$$

If the central bank alters the nominal exchange rate the speculator gains $W\left(f_{t}\right)$ plus the sale of foreign currency. If the central bank does not alter the nominal exchange rate the speculator gains $W_{t+1}$ plus the sale of foreign currency. The normalized Bellman equation for the central bank is,

$$
\begin{gathered}
V_{t}=\max _{p \in[0,1]}\left\{f_{t} q_{t}-\gamma\left|q_{t}-q^{*}\right|+\delta\left[p\left(V\left(f_{t}\right)-\beta-f_{t} q\left(f_{t}\right)\right)\right.\right. \\
\left.\left.+(1-p)\left(V_{t+1}-f_{t} q_{t+1}\right)\right]\right\}
\end{gathered}
$$


If the central bank alters the nominal exchange rate it pays the $\operatorname{cost} \beta$ and gains the value of the game with the new real exchange rate but must buy back all outstanding foreign currency balances at the new exchange rate. If it does not alter the nominal exchange rate it gains $V_{t+1}$ and must buy back outstanding foreign currency balances at the real exchange rate $q_{t+1}$. This is not, in fact, as odd as it at first appears. For analytical convenience speculators are thought of as selling their stock of foreign currency each period and then immediately choosing the level of foreign currency balances to purchase to bring forward to the next period. These foreign currency purchases are included in the values $V\left(f_{t}\right)$ and $V_{t+1}$. So while the central bank is thought of as buying back all outstanding foreign currency balances in the next state, this does not necessarily imply that the speculators will choose to carry zero foreign currency balances.

Both (19) and (20) are discounted, monotonic functions so they satisfy Blackwell's (1965) sufficient conditions for contraction mappings. Therefore for any $p \in \mathfrak{F}$, and any,$\in \mathfrak{F}^{-1}$ (19) has a nonempty set of optimal controls which will be denoted by $\mathfrak{R}^{\prime \prime}(\mathfrak{n}, \mathscr{\ell})$. Similarly, for any $f \in \mathfrak{F}$, and any $\mathscr{\ell} \in \mathfrak{F}^{-1},(20)$ has a nonempty set of optimal controls which will be denoted by $\mathfrak{R}(\mathcal{f}, \mathscr{\ell})$. Denoting the optimal controls for (17) as $\mathfrak{R}^{\prime}(\mathfrak{n}, \mathcal{f})$ a Markov perfect equilibrium is a fixed point

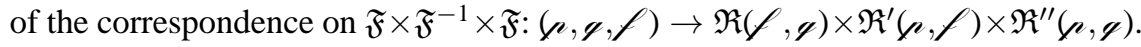

\subsection{Continuation value equilibrium}

To solve the problem, treat the endogenous function $V(\cdot)$ on the right hand side of (20) as exogenous and denote it $V \in \mathfrak{F}^{-1}$. By doing so the original game is replaced by a new game which terminates as soon as the central bank alters the nominal exchange rate, at which point it receives $V$. It must then buy back all outstanding foreign currency at the new exchange rate. A Markov continuation value equilibrium is characterized as $(\mathfrak{q}, \mathscr{\ell}, f, V) \in \mathfrak{F} \times \mathfrak{F}^{-1} \times \mathfrak{F} \times \mathfrak{F}^{-1}$, such that $\left(a_{V}, \mathscr{\vartheta}_{V}, f_{V}\right)$ are optimal controls of (20), (17), and (19) respectively. The continuation value equilibrium is an equilibrium of the original game if and only if $V=V(\cdot)$. Therefore the original infinite-horizon game is replaced by a family of finite horizon games, the solution to which reduces the fixed point problem in functional space $\mathfrak{F} \times \mathfrak{F}^{-1} \times \mathfrak{F}$ to a simpler fixed point problem in $\mathfrak{F}^{-1}$.

Necessary and sufficient conditions for the maximization of (19) are:

$$
\begin{array}{lll}
\text { if } \quad q_{t}+\alpha>\delta\left[p_{t} q\left(f_{t}\right)+\left(1-p_{t}\right) q_{t+1}\right] & \text { then } f_{i t}=0 \forall i \Rightarrow f_{t}=0 \\
\text { if } \quad q_{t}+\alpha<\delta\left[p_{t} q\left(f_{t}\right)+\left(1-p_{t}\right) q_{t+1}\right] & \text { then } f_{i t}=m / s \forall i \Rightarrow f_{t}=1 \\
\text { if } \quad q_{t}+\alpha=\delta\left[p_{t} q\left(f_{t}\right)+\left(1-p_{t}\right) q_{t+1}\right] & \text { then } f_{i t} \in[0, m / s] \forall i \Rightarrow f_{t} \in[0,1]
\end{array}
$$

Speculators compare the return on domestic currency with the return on foreign currency with the expected exchange rate in the next period. In the case of equality each is indifferent between holding domestic and foreign currency so each may hold any proportion of her wealth in foreign currency. Necessary and sufficient conditions for the maximization of (20) are: 


$$
\begin{array}{ll}
\text { if } \quad f_{t}\left(q\left(f_{t}\right)-q_{t+1}\right)<V\left(f_{t}\right)-\beta-V_{t+1} & \text { then } p_{t}=1 \\
\text { if } f_{t}\left(q\left(f_{t}\right)-q_{t+1}\right)>V\left(f_{t}\right)-\beta-V_{t+1} & \text { then } p_{t}=0 \\
\text { if } \quad f_{t}\left(q\left(f_{t}\right)-q_{t+1}\right)=V\left(f_{t}\right)-\beta-V_{t+1} & \text { then } p_{t} \in[0,1]
\end{array}
$$

The central bank compares the incremental cost of buying back outstanding foreign currency at the adjusted exchange rate (the LHS) with the increment in the normalized valuations from changing the exchange rate (the RHS). In the case of equality the central bank is indifferent and may set any probability of altering the nominal exchange rate.

Proposition 1. (i) In any Markov perfect equilibrium $V\left(q_{0}\right)<0$, moreover, $V_{t}<$ $0 \forall t \in \mathbb{R}_{+}$. (ii) $q\left(f_{t}\right)$ is nonincreasing in $f_{t}$ (iii) $V\left(f_{t}\right)$ is nonincreasing in $f_{t}$.

Proof. Appendix A.

\subsection{Critical states for deterministic exchange rate adjustment}

By examining the conditions under which deterministic exchange rate adjustment is possible, two critical states which play an important role in the players equilibrium strategies will emerge. Define deterministic exchange rate adjustment as $p_{t-1}=0$ and $p_{t}=1\left(p_{-1} \equiv 0\right)$. At state $t$ speculators are indifferent between holding wealth in foreign currency and holding it in domestic currency when,

$$
\begin{aligned}
q_{t}+\alpha & =\delta q\left(f_{t}\right) \\
q_{0} / \theta^{t} & =\delta q\left(f_{t}\right)-\alpha
\end{aligned}
$$

Solving for $t$, define over $x \in[0,1]$,

$$
\begin{array}{lll}
\tau(x) \equiv \frac{\ln \left[q_{0} /(\delta q(x)-\alpha)\right]}{\ln (\theta)} & \forall x \text { where } \delta q(x)>\alpha \\
\tau(x) \equiv+\infty & \forall x \text { where } \delta q(x) \leq \alpha
\end{array}
$$

$\tau(0)>0$ and, since $q\left(f_{t}\right)$ is nonincreasing in $f_{t}, \tau(x)$ is nondecreasing in $x$. If $t \leq \tau(0)$ speculation is not profitable, even in the face of a certain exchange rate adjustment. If $t \geq \tau(1)$ then, if the central bank is pursuing a policy of deterministic exchange rate adjustment, each speculators will try to hold all of her wealth in foreign currency. Aggregate speculation will be limited to one by central bank reserves. If $t=\tau(x)$ with $x \in(0,1)$ then deterministic exchange rate adjustment will induce aggregate speculation of $x$. If aggregate speculation is less than $x$ then the central bank will choose an exchange rate greater than $q(x)$ so speculation will be strictly preferred by each speculator. Conversely, if aggregate speculation is greater than $x$, the central bank will choose an exchange rate less than $q(x)$ so each speculator will prefer to hold all her wealth in the domestic currency. In the face of an uncertain exchange rate adjustment $f_{\tau(x)}<x$. for $x \in(0,1]$. 
Now consider the problem from the central bank's perspective. Assume that $t>\tau(1)$ and that $p_{t}=1$ so $f_{t}=1$. Therefore, if this state arrives the central bank will lose

$$
\delta q(1)-q_{t}
$$

which is increasing in $t$, since $q_{t}=\left(q_{0} / \theta^{t}\right)$. If this cost is too high the central bank will try to avoid it by having a positive probability of devaluation in the previous period, $p_{t-1}>0$. This suggests that there exists a critical state $\mu$ such that deterministic exchange rate adjustment with full speculation is suboptimal for the central bank for $t>\mu$. The following proposition formalizes this intuitive claim.

Proposition 2. There exists a function $\tau(x)>0$ defined on $x \in[0,1]$ and $\mu>0$ such that in any continuation value equilibrium: (i) $\forall t \leq \tau(0), f_{t}=0$. (ii) $\forall x \in(0,1]$ if $t=\tau(x)$ then $f_{t} \leq x$ and, if $p_{t}=1, f_{t}=x$. (iii) $\forall t \geq \tau(1)$, if $p_{t}=1$, $f_{t}=1$. (iv) $\forall t \geq 1$ if $t>\max (\tau(1), \mu)$ and $p_{t}=1$ then $p_{t-1}>0$. (v) $\forall t$ such that $q_{t} \geq q^{*}$, if $p_{t}=1$ then $p_{t-1}>0$.

where,

$$
\mu=\frac{\ln \left[(\theta-1) q_{0} /\left(\theta q^{*}\right)\right]}{\ln (\theta)}
$$

Proof. Appendix B.

The critical results here are that there can be no deterministic exchange rate adjustment in states where $q_{t} \geq q^{*}$ or in states $t>\max [\tau(1), \mu]$.

The nature of the continuation value equilibrium, and therefore of the complete game, can now be established. It will be shown that, in general, the equilibrium consists of three phases separated by critical states $\underline{T}$ and $\bar{T}$ : pure strategies in the phase $t \in[0, \underline{T})$, mixed strategies during the phase $t \in[\underline{T}, \bar{T})$, and then pure strategies in the phase $t \in[\bar{T}, \infty)$.

\subsection{The pure strategy phases}

It is necessary to show that there exists $T^{*}$ and $\bar{T}$ such that $p_{t}=0 \forall t<$ $\min \left(T^{*}, \tau(0)-1\right)$ and $p_{t}=1 \forall t>\bar{T}$. To find $T^{*}$ consider a case where the public never speculates, $f_{t}=0 \forall t \in \mathbb{R}_{+}$. The opportunity cost of postponing exchange rate adjustment one period is $(1-\delta)(V(0)-\beta)$. If $q_{t+1}>q^{*}$ the gain from postponing is $-\gamma\left[q_{t+1}-q^{*}\right]$ which is increasing in $t$ so the central bank will not devalue when $q_{t+1}>q^{*}$. If $q_{t+1} \leq q^{*}$ the gain from postponing devaluation one period is $\gamma\left[q_{t+1}-q^{*}\right]$, which is decreasing in $t$. At $q_{t}=q^{*}$ the gain from postponing is greater than the opportunity cost. However, as inflation erodes the real exchange rate the gain from postponing declines. The central bank will devalue at the first state greater than or equal to $T^{*}$ defined by,

$$
\gamma\left[q_{T^{*}+1}-q^{*}\right]=(1-\delta)(V(0)-\beta)
$$


Now consider the other extreme where the public always speculates, $f_{t}=$ $1 \forall t \in \mathbb{R}_{+}$. The opportunity cost of postponing exchange rate adjustment one period is then $(1-\delta)(V(1)-\beta-q(1))$. If $q_{t+1}>q^{*}$ the gain from postponing is still $-\gamma\left[q_{t+1}-q^{*}\right]$ which is increasing in $t$ so the central bank will not devalue when $q_{t+1}>q *$. If $q_{t+1} \leq q^{*}$ the gain from postponing devaluation one period is $\gamma\left[q_{t+1}-q^{*}\right]$, which is decreasing in $t$. At $q_{t}=q^{*}$ the gain from postponing is greater than the opportunity cost. However, as inflation erodes the real exchange rate the gain from postponing declines. The central bank will devalue at the first state greater than or equal to $\bar{T}$ defined by,

$$
\gamma\left[q_{\bar{T}+1}-q^{*}\right]=(1-\delta)(V(1)-\beta-q(1))
$$

By proposition $1,0>V(0) \geq V(1)$ so $q_{T^{*}+1}>q_{\bar{T}+1}$ and $\bar{T}+1>T^{*}+1>0$. The strategy $q(1)=q^{*}$ and then $p_{t}=1, q\left(f_{t}\right)=q^{*}$ for all future states, is always feasible which provides a lower bound $V(1) \geq q(1)+\delta[V(1)-\beta-q(1)]$ or, equivalently, $(1-\delta)[V(1)-\beta-q(1)] \geq-\beta$. Combined with (25) this yields $\gamma\left[q_{\bar{T}+1}-q^{*}\right] \geq-\beta$. Therefore $q_{\bar{T}+1} \geq q^{*}-\beta / \gamma>0$, which implies $\bar{T}+1<\infty$. These critical states $\bar{T}$ and $T^{*}$ determine adjustment when speculators always try to hold all their wealth in foreign currency and when they never hold any foreign currency, respectively. They also provide bounds on the equilibrium adjustment state, formalized as follows,

Proposition 3. In any continuation value equilibrium: (i) if $t<\min \left(T^{*}, \tau(0)-1\right)$ then $p_{t}=0$. (ii) if $t>\bar{T}$ or $t=\bar{T} \leq \tau(0)$ then $p_{t}=1$. (iii) if $t=\bar{T}>\tau(1)$ then $f_{t}=1$ and $p_{t} \geq\left[q_{t}-\delta q_{t+1}+\alpha\right] / \delta\left[\left(q(1)-q_{t+1}\right)\right]$.

\section{Proof. Appendix C.}

The game begins with a phase of pure strategies, $t<\min \left(T^{*}, \tau(0)-1\right)$, where $p_{t}=f_{t}=0$. In this phase the central bank does not alter the nominal exchange rate and individuals do not hold foreign currency for speculative purposes. The rest of proposition 3 states that the game ends with a phase of pure strategies, $t>\max (\bar{T}, \tau(1))$, where $p_{t}=f_{t}=1$. In this phase individuals try to hold all their wealth in foreign currency in anticipation of devaluation. However, in aggregate they are unable to do so since their speculation totally depletes the central bank's foreign currency reserves. Although the central bank could set a low probability of devaluation to deter this speculation, it has become too costly to wait, and it devalues with certainty.

\subsection{The mixed strategy phase}

The probability of devaluation which leaves speculators indifferent between $f_{t} \in$ $[0, m / s]$ is given by,

$$
q_{t}+\alpha=\delta\left[p_{t} q\left(f_{t}\right)+\left(1-p_{t}\right) q_{t+1}\right]
$$

Solving for $p_{t}$, 


$$
p_{t}=\frac{q_{t}-\delta q_{t+1}+\alpha}{\delta\left[q\left(f_{t}\right)-q_{t+1}\right]}=\frac{\theta^{-t}((\theta-\delta) / \delta \theta)+(\alpha / \delta q(0))}{\theta^{-h(f)}-\theta^{-(t+1)}}
$$

where $h\left(f_{t}\right)$ is defined by,

$$
q\left(f_{t}\right)=q(0) / \theta^{h(f)}
$$

$h\left(f_{t}\right)<t+1$ since otherwise speculators would strictly prefer $f_{t}=0 \Rightarrow k\left(f_{t}\right)=0$. Since $t>\tau(1)$ implies $q_{t}+\alpha<\delta q(1)$ and (26) yields $p_{t}<1 \forall t>\tau(1)$ during this phase.

The aggregate public holdings of foreign currency which leave the central bank indifferent between $p_{t} \in[0,1]$ are given by,

$$
f_{t}=\frac{V\left(f_{t}\right)-\beta-V_{t+1}}{q\left(f_{t}\right)-q_{t+1}}
$$

Since $p_{t+1}=1$ is always possible, by (20),

$$
V_{t+1} \geq f_{t+1} q_{t+1}-\gamma\left|q_{t+1}-q^{*}\right|+\delta\left[V\left(f_{t+1}\right)-\beta-f_{t+1} q_{t+1}\right]
$$

which holds with equality if $p_{t+1}>0$. So, during the mixed strategy phase $f_{t}$ follows the difference equation:

$$
f_{t}=\frac{V\left(f_{t}\right)-\delta V\left(f_{t+1}\right)-(1-\delta) \beta+\gamma\left|q_{t+1}-q^{*}\right|}{q\left(f_{t}\right)-q_{t+1}}+\frac{\left[\delta q\left(f_{t+1}\right)-q_{t+1}\right]}{q\left(f_{t}\right)-q_{t+1}} \cdot f_{t+1}
$$

Therefore, define,

$$
\begin{gathered}
z_{t, V}\left(\psi_{t}\right)=\frac{\theta^{-t}((\theta-\delta) / \delta \theta)+(\alpha / \delta q(0))}{\theta^{-h(\psi)}-\theta^{-(t+1)}} \\
P_{V}:\left(t, \psi_{t}\right) \in \mathbb{R}_{+} \times \mathbb{R} \rightarrow P_{t, V}\left(\psi_{t}\right)=\min \left\{1, z_{t}\left(\psi_{t}\right)\right\}
\end{gathered}
$$

and implicitly define $\psi_{t, V}:(t, y) \in[\tau(0)-1, \infty) \times \mathbb{R} \rightarrow \psi_{t, V}(y)$ as:

$$
\psi_{t, V}(y)=\frac{V\left(\psi_{t}\right)-\delta V(y)-(1-\delta) \beta+\gamma\left|q_{t+1}-q^{*}\right|}{q\left(\psi_{t}\right)-q_{t+1}}+\frac{\left[\delta q(y)-q_{t+1}\right]}{q\left(\psi_{t}\right)-q_{t+1}} \cdot y
$$

During the phase of mixed strategies, $p_{t}=P_{t}$, by (26) and $f_{t}=\psi_{t}$, by (29). Since $f_{t}=1$ for $t>\max \{\bar{T}, \tau(1)\}$, by propositions 2 and $3, f_{t}$ can be constructed by backward induction. Implicitly define $F: t \in[\tau(0)-1, \infty) \rightarrow F_{t, V}$ as,

and, if $\bar{T} \geq \tau(1)$,

$$
F_{t, V}=1 \quad \text { on }[\max (\bar{T}, \tau(1)), \infty)
$$

$$
\begin{aligned}
& \text { if } \bar{T} \in(\tau(0)-1, \tau(1)) \text {, } \\
& F_{t, V}=\psi_{t, V}\left(F_{t+1, V}\right)=\psi_{t, V} \circ \cdots \circ \psi_{t+k, V}(1) \quad \text { on }[\tau(0)-1, \bar{T}) \\
& F_{t, V}=\psi_{t, V}\left(F_{t+1, V}\right)=\psi_{t, V} \circ \cdots \circ \psi_{t+k, V}\left(x_{\bar{T}}\right) \quad \text { on }[\tau(0)-1, \bar{T}) \\
& F_{t, V}=x_{t} \quad \text { on }[\bar{T}, \tau(1))
\end{aligned}
$$

where $k=\min \{j \in N \mid t+j+1 \geq \bar{T}\}$ and $x_{t}$ is defined on $x_{t} \in[0,1]$ by $t=\tau\left(x_{t}\right)$. The subscripts $V$ will be omitted when no confusion will result. In the mixed strategy phase $f_{t}=F_{t}$. Proposition 4 describes the dynamics of $p_{t}$ and $f_{t}$ during the mixed strategy phase. 
Proposition 4. (i) $\forall V$ such that $\bar{T}>\tau(0)-1$, the function $F_{V}: t \rightarrow F_{t, V}$ is increasing on $[\tau(0)-1, \bar{T}]$. (ii) The function $P_{V}: t \rightarrow P_{t, V}$ is equal to one for $t \leq \tau(0)$, and then decreasing to its limit $P_{\infty, V}=\alpha / \delta q(1)$.

\section{Proof. Appendix D.}

The central bank's desire to deter speculation implies that in the mixed strategy phase the probability of a devaluation is decreasing. Successful speculation is becoming increasingly profitable during this phase, as the potential devaluation becomes larger. Therefore, in order to continue to deter speculation the central bank must convince speculators that success is less likely.

Since $F_{t} \in(0,1)$ implies that the central bank is indifferent between $p_{t} \in$ $[0,1]$ so $p_{t}=0$ is strictly preferred by the central bank when $F_{t}<0$. Conversely, $p_{t}=1$ is strictly preferred when $F_{t}>1$. Since $F_{\bar{T}}=1$, the state $\underline{T}$ at which the central bank first has a positive probability of devaluation can be computed by backward induction from $\bar{T}$ and looking for the first (as $t$ decreases) non-positive value of the function $F_{t}$. Define $\underline{T}(V)$ by,

$$
\begin{array}{ll}
\text { if } T^{*}(V) \leq \tau(0)-1 & \text { then } \underline{T}(V)=T^{*}(V) \\
\text { if } T^{*}(V)>\tau(0)-1 & \text { then } \underline{T}(V)=\min \left\{t \in[\tau(0)-1, \bar{T}(V)] \mid F_{t, V} \geq 0\right\}
\end{array}
$$

Therefore, $\underline{T}>0, p_{t}=f_{t}=0$ for states less than $\underline{T}$ and, $p_{t} \in(0,1), f_{t} \in(0,1)$ for $t \in(\underline{T}, \bar{T})$.

Proposition 5. (i) $\underline{T}(V) \leq T^{*}(V)$. (ii) if $T^{*}(V)>\tau(0)-1, \underline{T}(V)<T^{*}(V)$. (iii) $q_{0}<\infty$.

\section{Proof. Appendix E.}

If $T^{*}(V) \leq \tau(0)-1$ the central bank will devalue before speculation becomes profitable and it will follow a deterministic $(S, s)$ rule. However, if $T^{*}(V)>\tau(0)-1$, speculators will try to purchase foreign currency just before the devaluation and the central bank will try to randomize the timing of the devaluation so as to devalue just before they do so. This causes the devaluation to occur, potentially, before it would in the absence of speculation $\left(T(V)<T^{*}(V)\right)$. This implies that either there will be no speculation and the central bank will devalue at $T^{*}(V)$ or there will be speculation and the central bank will follow a mixed strategy during the phase $t \in[\underline{T}(V), \bar{T}(V)]$ but will be precisely indifferent between this strategy and simply devaluing at $T^{*}(V)$.

The intuition for this result is instructive and quite general. While the speculators choose their foreign currency holdings simultaneously, it is helpful here to think of them queuing at the foreign exchange desk. If there is a positive probability of devaluation the first speculator will purchase foreign currency. This purchase makes devaluation a little less attractive to the central bank. Speculators will continue to purchase foreign currency up to the point where the central bank is indifferent between devaluing and maintaining the exchange rate one more period. At this point if the next speculator purchased foreign currency the central bank would strictly prefer not to devalue so the speculator will not 
make the purchase. Therefore, during the entire mixed strategy phase, which includes the no speculation devaluation point, the central bank is indifferent between devaluing and waiting one more period. This implies that the central bank is indifferent between the mixed strategy and a pure strategy of devaluing with certainty at the point that it would if there were no speculation. It is important to point out that this pure strategy is not part of a Nash equilibrium. The indifference result is, however, an important implication of the actual mixed strategy Nash equilibrium.

\section{Intuition}

The formal derivation of the equilibrium is given in the previous section. This section aims to provide an intuitive understanding of the equilibrium. Depending on parameter values the continuation value equilibrium, and therefore equilibrium of the complete game, can take one of two basic forms.

\subsection{Strong capital controls: deterministic outcome}

With relatively low cost of devaluing the exchange rate, $\beta$, relatively high cost of deviations from the target real exchange rate, $\gamma$, and high cost of holding foreign currency, $\alpha, \bar{T}<\tau(0)$ so the central bank devalues often, but by a small amount. The small devaluations and strong capital controls imply that in equilibrium speculation is not profitable, even though its timing is known with certainty. This implies that the central bank pursues a deterministic $(S, s)$ rule and that there is no speculation by individuals on the equilibrium path. Thus with very onerous capital controls the equilibrium is observationally equivalent to the equilibrium derived in work with perfect capital controls, Flood and Marion (1997a). ${ }^{10}$

\subsection{Capital mobility: mixed-strategy equilibrium with a stochastic outcome}

With a relatively high cost of devaluing the exchange rate, $\beta$, relatively low cost of deviations from the target real exchange rate, $\gamma$, and low cost of holding foreign currency, $\alpha$, a qualitatively different equilibrium emerges. The central bank makes infrequent devaluations which are large relative to speculators' cost of holding foreign currency. Thus successful speculation will be profitable. The central bank is well aware that if speculators know the date of the devaluation they will engage in a speculative attack. To avoid such an attack the central bank must introduce uncertainty into the decisions of speculators. Thus the equilibrium will be in mixed strategies (shown in Fig. 1).

\footnotetext{
${ }^{10}$ However off the equilibrium path the central bank may be playing a mixed strategy.
} 

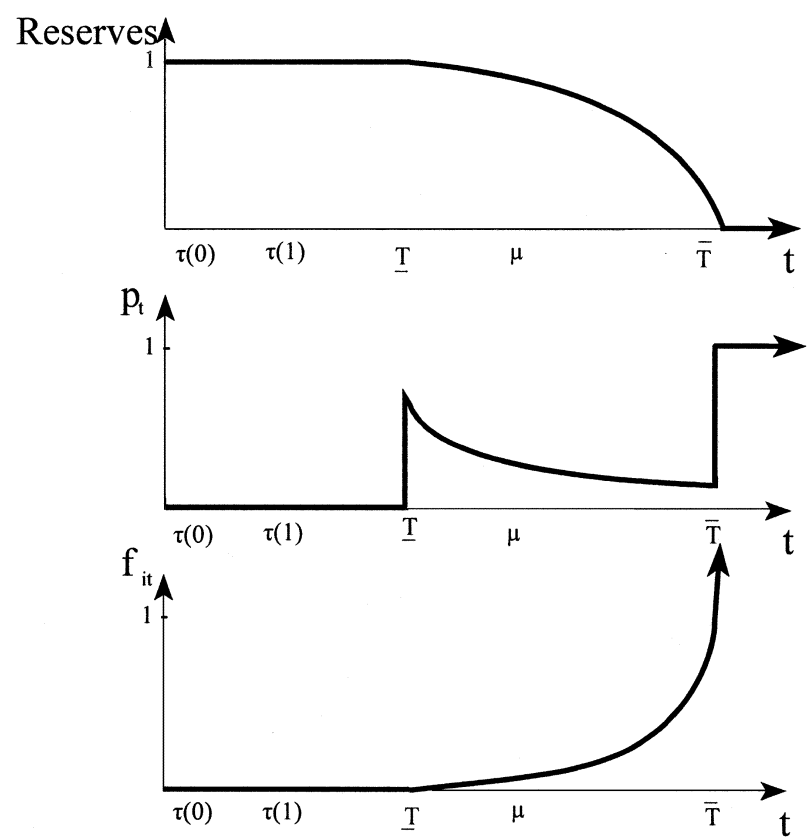

Figure 1. Mixed strategy equilibrium, stochastic outcome. Central bank reserves, probability of devaluation, and speculators' desired holdings of foreign currency in equilibrium of the continuation game. A devaluation ends the continuation game and a new game starts with a lower $t$ (increased real exchange rate)

The probability of devaluation and speculative foreign currency balances are both zero for $t<\underline{T}$. In each period thereafter, $t \geq \underline{T}$, there is a positive probability $p_{t}$ that a devaluation occurs, given that it has not occurred earlier. If the devaluation has not occurred by state $\bar{T}$ then it occurs with certainty. Speculators hold increasing foreign currency balances in anticipation of devaluation. If the game ever reaches a state $t \geq \bar{T}$, there is a run on central bank reserves and desired speculative balances are greater than foreign currency reserves. Whenever it occurs, the devaluation is to a real exchange rate which is a decreasing function of the level of foreign currency held by the public. Therefore, the central bank follows a modified $(\hat{S}, \hat{S})$ rule, where $\hat{S}$ and $\hat{S}$ represent random variables.

During the phase of mixed strategies the probability of devaluation is $d e$ creasing. This surprising result is driven by the central bank's need to deter speculation. If the probability of devaluation were constant, a later state would make speculation more attractive to an individual speculator. Not only is the gain to successful speculation $\left(\delta q\left(f_{t}\right)-q_{t}-\alpha\right)$ increasing in $t$ (holding aggregate speculation constant), but the cost of unsuccessful speculation $\left(q_{t}-\delta q_{t+1}+\alpha\right)$ is decreasing in $t$. Therefore, to deter increased speculation, the central bank must have a decreasing probability of devaluation. Since it will devalue with certainty at $t \geq \bar{T}$, the expected time to the next devaluation may be either increasing or decreasing in $t$, but the probability of devaluation at state $\mathrm{t}$ must be decreasing. 
This result depends, in part, on the simple specification of the opportunity cost of holding foreign currency, which is assumed to be constant, $\alpha$. In a fully specified monetary model the opportunity cost would itself depend on the aggregate level of speculation through the interest rate. Thus in such a model deterring speculation would be somewhat less difficult and so the probability of devaluation would not have to decline as quickly. If the interest rate was very responsive to the level of speculation, as it would be if central bank reserves were large relative to the money supply, then the probability of devaluation could be increasing. What is interesting here is that when we endogenize the central bank's behavior in response to speculation, it is no longer obvious that the probability of devaluation is monotonic in its target variable (in this case the real exchange rate). The central bank will try to discourage speculation, and this creates an incentive to lower the probability of devaluation as the expected size of the devaluation gets larger.

The incentive to deter speculation is not analyzed in the existing literature which takes either central bank behavior or speculator behavior as exogenous. This literature predicts that the central bank's probability of devaluation will be strictly monotonic and increasing in its target variables. Thus nearly all empirical work which attempts to identify central bank target variables uses methods which assume this ex ante. However, if central banks are actually trying to deter speculation, these approaches may miss important determinants of central bank behavior simply because they are based on models without strategic interaction between the central bank and foreign currency speculators. Whether this simplification is warranted is an empirical matter which has not yet been fully explored. The one empirical paper which I am aware of which does use a framework which permits non-monotonic evolution of the probability of devaluation, Klein and Marion (1997), does find some evidence suggesting that devaluation probabilities may be decreasing in early dates.

Despite its best efforts to deter speculation, the central bank is only partially successful. Speculators are aware that at some point the cental bank will devalue. Thus private holdings of foreign currency are increasing over time, always keeping the central bank indifferent between devaluing and waiting. If the aggregate level of speculation were constant, both the cost of devaluation $\left(f_{t}\left[q\left(f_{t}\right)-q_{t+1}\right]+\beta\right)$ and the benefit $\left(V\left(f_{t}\right)-V_{t+1}\right)$ would be increasing in $t$, but the benefit would be increasing faster than the cost. Therefore, during the mixed strategy phase speculative holdings of foreign currency are increasing (and central bank foreign currency reserves are decreasing) until $t \geq \bar{T}$. If a devaluation does not occur before $t \geq \bar{T}$, then speculators will wish to hold all of their wealth in foreign currency. Since foreign currency reserves are limited, this run on the bank totally depletes its reserves.

The intuitive explanation for the discontinuous profile of $p_{t}$ is best understood by considering the outcome if there is never any speculation. In that case the central bank would devalue with probability one at $T^{*}$ resulting in a unit discontinuity in $p_{t}$ at $T^{*}$. In the presence of speculation it spreads out the probability mass on both sides of $T^{*}$ with parts of the original discontinuity remaining 


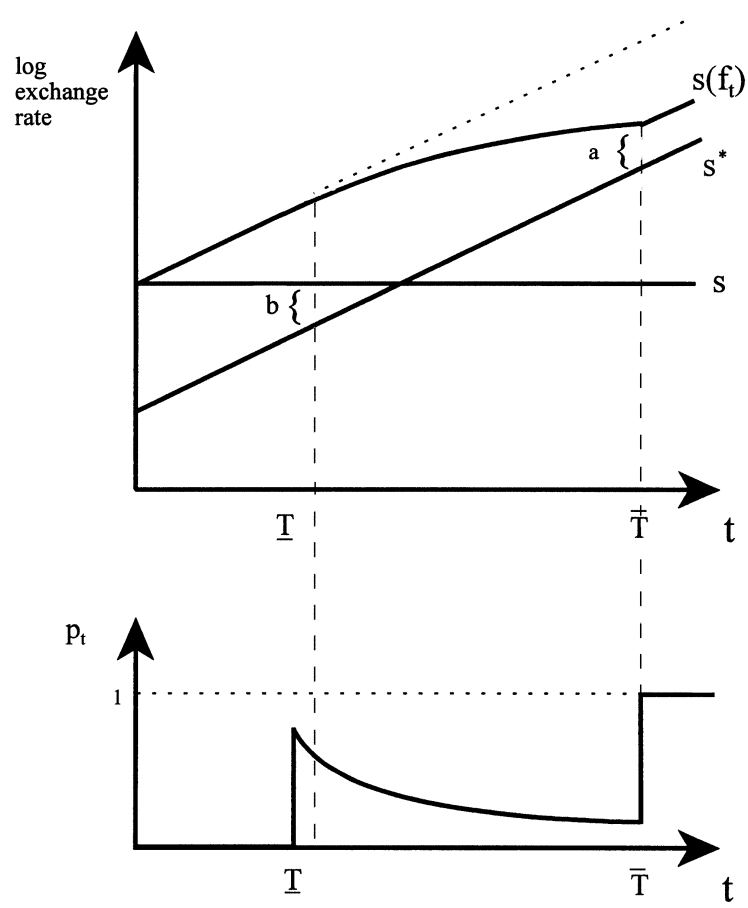

Figure 2. Mixed strategy equilibrium, stochastic outcome. The nominal exchange rate - fixed $s$, target $s^{*}$, and post-devaluation $s\left(f_{t}\right)$ - and the probability of devaluation in equilibrium of the continuation game. A devaluation ends the continuation game and starts a new continuation game

at the extremities. On $\left[\underline{T}, T^{*}\right]$ the central bank attempts to take advantage of the public's low foreign currency holdings, while on $\left[T^{*}, \bar{T}\right]$ large speculative balances make devaluation increasingly costly. However, at $\bar{T}$ it has become too costly to wait, and the central bank devalues with certainty.

During the mixed strategy phase the post devaluation nominal exchange is increasing at a rate less than the inflation differential, $\pi$, due to the increasing private speculative holdings of foreign currency. Figure 2 provides a method of examining the situation immediately after a devaluation. This is done by realizing that a devaluation causes $s\left(f_{t}\right)$ to become the new nominal exchange rate. The relationship between this exchange rate and the target exchange rate $s^{*}$ determines the new state. Consider a devaluation which occurs at $\bar{T}$. At the state of the devaluation the distance between $s\left(f_{t}\right)$ and $s^{*}$ (labeled 'a') is equal to the distance between $s$ and $s^{*}$ in the new post-devaluation state (labeled ' $\mathrm{b}$ '). The $y$-axis is then rescaled and the game continues from that state.

The graph is drawn so that the post devaluation state is greater than $\underline{T}$. This is not necessarily the case but it is possible if reserves are large and the cost of devaluation is small. In this case there is a positive probability of a devaluation immediately after the first devaluation. The first devaluation is forced by speculation and the large discrepancy between $s$ and $s^{*}$. After the devaluation 
speculators realize that the central bank no longer has such a strong desire to devalue since $s$ is closer to the target exchange rate, so if they hold such large foreign currency balances the central bank will choose not to devalue. Therefore in equilibrium they sell some of their foreign currency, up to the point where the central bank is indifferent between devaluing and maintaining the new exchange rate. Now that there is less foreign currency in the hands of speculators devaluation is less costly, and the central bank may devalue again immediately. Therefore the model implies that smaller devaluations just after a large devaluation may be the result of optimal central bank policy rather than the result of miscalculations in the original devaluation.

\section{Conclusion and implications}

This paper analyzes optimal devaluation policy in a fixed exchange rate regime. If the political and economic costs of altering the nominal exchange rate are small and speculators' costs of holding foreign currency are very high, deterministic devaluation policies may be optimal for the central bank. In this case, speculation is not profitable even when the timing of devaluation is known with certainty.

However, if capital is mobile deterministic devaluation policies are suboptimal. In other words, there does not exist a Nash equilibrium where the central bank adopts a pure strategy of devaluing at a certain date. If the central bank was to follow such a deterministic policy, speculators would buy foreign currency in a sudden attack just before the devaluation. But in this case the central bank would prefer to devalue just before the attack, leading to an even earlier attack. Thus whenever the potential devaluation is large enough that successful speculation is profitable, the equilibrium will exist only in mixed strategies. ${ }^{11}$

In the mixed strategy phase of the Markov Perfect equilibrium the difference between the pre-devaluation nominal exchange rate and the post-devaluation nominal exchange rate is increasing, so successful speculation is increasingly profitable. However, during this period speculators are indifferent between attacking and not since the probability of devaluation is decreasing. While the central bank is trying to deter a speculative attack, speculators hold increasing foreign currency balances. In fact, their foreign currency holdings are increasing at an accelerating rate, but the expected profits from holding foreign currency are zero. However, ex post, the profits from holding foreign currency during a devaluation can be substantial. Eventually, however, if a devaluation has not yet

\footnotetext{
11 Karim Abadir and Harald Uhlig independently pointed out that the central bank's problem has much in common with the classic "Surprise Quiz" game. In that game a professor promises the students that there will be a surprise quiz in the coming week. If the quiz does not occur by Thursday, then the students know that it must occur on Friday, and thus it is not a surprise. So the professor cannot play a pure strategy of having the exam on Friday. But if the exam has not occurred by Wednesday the students know it must occur on Thursday, and it will not be a surprise. So the professor cannot play a pure strategy of having the exam on Thursday. Backwards induction via the same argument eliminates any pure-strategy for the professor. Similarly, the central bank would like to have the devaluation of the fixed exchange rate come as a surprise to speculators, and so for the same reason it cannot play a pure-strategy.
} 
arrived, the central bank's reserves reach a critically low level, and the probability of devaluation jumps to one. At this point speculation yields strictly positive profits, even ex ante. So all speculators purchase as much foreign currency as possible, fully depleting the central bank's reserves and devaluation occurs with certainty.

This possibility of non-monotonic devaluation probabilities arises here because the cental bank is explicitly trying to avoid speculation. The theoretical literature has not permitted this possibility, and therefore very little empirical work has been done to test whether devaluation probabilities are monotonic in central banks' target variables. However, the work that has been done by Klein and Marion (1997) suggests that for some periods probabilities of devaluation may be decreasing. Together with the results of this paper, these findings suggest that central banks may in fact be actively trying to deter speculation.

Note that one of the arguments often cited in favor of the fixed exchange rates is that they may decrease the exchange rate uncertainty inherent in a flexible exchange rate system. This may potentially lead to welfare improvements through increased trade volume and foreign direct investment. This model suggest that in practice the incentives of the central bank may lead it to reintroduce much of the exchange rate uncertainty in an attempt to avoid speculative attacks. This suggests that the time near an devaluation of a fixed exchange rate is likely to be characterized by a high degree of uncertainty. This uncertainty is not an exogenous feature of fixed exchange rates but rather is introduced endogenously and deliberately by the central bank in an attempt to devalue before a speculative attack.

The seminal work of Harsanyi (1973) provides an additional interpretation of this endogenous uncertainty. If speculators were unsure of the objective function being used by the central bank, or about the current level of reserves, then the central bank would follow a pure strategy. However, equilibrium uncertainty would be present due to this exogenous uncertainty about the central bank's objective function. Harsanyi's insight is that as this exogenous uncertainty goes to zero, the equilibrium uncertainty does not. In fact, the probability of devaluing the fixed exchange rate at each time approaches the probabilities found in the model. This remarkable fact implies that even arbitrarily small uncertainty about the central bank's objective function or foreign currency reserves will lead to very large uncertainty about the conditions under which the central bank will devalue the fixed exchange rate regime.

\section{Appendix A: Proof of Proposition 1}

(i) For $V\left(q_{0}\right) \geq 0$ or $V_{t} \geq 0$ it is necessary that the central bank is making an expected gain on foreign currency transactions $\Rightarrow \exists t \geq 0$ such that $f_{t}>0$ and:

$$
q_{t} f_{t}-\delta\left[p_{t} f_{t} q\left(f_{t}\right)+\left(1-p_{t}\right) f_{t} q_{t+1}\right]>0
$$

From (21) $f_{t}>0$ implies, 


$$
\begin{aligned}
& q_{t}+\alpha \leq \delta\left[p_{t} q\left(f_{t}\right)+\left(1-p_{t}\right) q_{t+1}\right] \\
& q_{t} f_{t}-\delta\left[p_{t} f_{t} q\left(f_{t}\right)+\left(1-p_{t}\right) f_{t} q_{t+1}\right] \leq-\alpha f_{t}
\end{aligned}
$$

Which contradicts (A1), so all speculation is harmful to the central bank and (i) is proven.

(ii) From (17) $q\left(f_{t}\right)$ is the optimal control of,

$$
\mathscr{U}_{C B}\left(f_{t}\right)=\max _{q \in(0, \infty)}\left\{V(q)-f_{t} q\right\}
$$

so $f \Rightarrow q$ and $f^{\prime} \Rightarrow q^{\prime}$. Assume $f<f^{\prime}$, revealed preference implies,

$$
\begin{aligned}
& V(q)-f q \geq V\left(q^{\prime}\right)-f q^{\prime} \\
& f\left(q^{\prime}-q\right) \geq V\left(q^{\prime}\right)-V(q)
\end{aligned}
$$

and,

$$
\begin{aligned}
& V\left(q^{\prime}\right)-f^{\prime} q^{\prime} \geq V(q)-f^{\prime} q \\
& V\left(q^{\prime}\right)-V(q) \geq f^{\prime}\left(q^{\prime}-q\right)
\end{aligned}
$$

Combining this with (A2) gives,

$$
\begin{gathered}
f\left(q^{\prime}-q\right) \geq f^{\prime}\left(q^{\prime}-q\right) \\
\left(f^{\prime}-f\right)\left(q^{\prime}-q\right) \leq 0
\end{gathered}
$$

which implies that $q \geq q^{\prime}$ proving (ii).

(iii) Assume $V\left(q^{\prime}\right)>V(q)$, then (A2) implies, $f\left(q^{\prime}-q\right)>0 \Rightarrow q^{\prime}>q$, a contradiction, which proves (iii).

\section{Appendix B: Proof of Proposition 2}

(i), (ii) and (iii) shown in text.

The proof of (v) is a subset of the proof of (iv) $\forall t \geq \tau(1)-1, q_{t+1} \leq q_{\tau(1)}$ so, from the definition of $\tau(1)$,

$$
q_{t+1} \leq \delta q(1)-\alpha<\delta q(1)
$$

Therefore,

$$
\forall t \geq \tau(1) \quad q_{t+1}<\delta q(1)
$$

Now assume that (iv) does not hold, $t \geq 1, t>\tau(1)$ and $p_{t}=1$. Since, $p_{t-1}=0$, (21) requires $f_{t-1}=0$ and $f_{t}=1$ from (iii). There are two cases: $q_{t}<q^{*}$ and $q_{t} \geq q^{*}$.

Case I: $q_{t}<q^{*}$. It is possible for the central bank to choose $p_{t+1}=1$ and then $q(1)$ which puts a lower bound on its payoff in period $t+1$, from (20):

$$
\begin{aligned}
& V_{t+1} \geq q_{t+1} f_{t+1}+\gamma\left[q_{t+1}-q^{*}\right]+\delta[V(1)-\beta]-\delta q(1) f_{t+1} \\
& V(1)-\beta-V_{t+1} \leq(1-\delta)(V(1)-\beta)-f_{t+1}\left(q_{t+1}-\delta q(1)\right)-\gamma\left[q_{t+1}-q^{*}\right]
\end{aligned}
$$


Since $p_{t}=f_{t}=1$ and $q\left(f_{t}\right)$ is nonincreasing in $f_{t}$, (22) requires,

$$
q(1)-q_{t+1} \leq V(1)-\beta-V_{t+1}
$$

Combining the two,

$$
\begin{aligned}
& q(1)-q_{t+1} \leq(1-\delta)(V(1)-\beta)-f_{t+1}\left(q_{t+1}-\delta q(1)\right)-\gamma\left[q_{t+1}-q^{*}\right] \\
& (1-\delta)(V(1)-\beta) \geq q(1)-q_{t+1}+f_{t+1}\left(q_{t+1}-\delta q(1)\right)+\gamma\left[q_{t+1}-q^{*}\right]
\end{aligned}
$$

Since $p_{t}=f_{t}=1$, (20) implies,

$$
V_{t}=q_{t}+\gamma\left[q_{t}-q^{*}\right]+\delta[V(1)-\beta]-\delta q(1)
$$

$p_{t-1}=f_{t-1}=0$ and (22) yield,

$$
0 \geq V(0)-\beta-V_{t}
$$

By proposition $1, V(1) \leq V(0) \Rightarrow V_{t} \geq V(1)-\beta$ so (B3) gives,

$$
\begin{aligned}
& V(1)-\beta \leq q_{t}+\gamma\left[q_{t}-q^{*}\right]+\delta[V(1)-\beta]-\delta q(1) \\
& (1-\delta)(V(1)-\beta) \leq q_{t}-\delta q(1)+\gamma\left[q_{t}-q^{*}\right]
\end{aligned}
$$

Therefore (B2) implies,

$$
q(1)-q_{t+1}+f_{t+1}\left(q_{t+1}-\delta q(1)\right)+\gamma\left[q_{t+1}-q^{*}\right] \leq q_{t}-\delta q(1)+\gamma\left[q_{t}-q^{*}\right]
$$

Rearranging terms,

$$
\gamma q_{t+1}-(1+\gamma) q_{t}+q(1) \leq\left(1-f_{t+1}\right)\left(q_{t+1}-\delta q(1)\right)
$$

The R.H.S. $\leq 0$ by (B1) so,

$$
\gamma\left(q_{0} / \theta^{t+1}\right)-(1+\gamma)\left(q_{0} / \theta^{t}\right) \leq-q(1)
$$

Solving for $t$,

$$
t \leq \frac{\ln \left[(\theta-1) q_{0} /\left(\theta q^{*}\right)\right]}{\ln (\theta)} \equiv \mu
$$

Therefore if $q_{t}<q^{*}$, this condition is required for the combination $p_{t-1}=0$ and $p_{t}=1$.

Case II: $q_{t} \geq q^{*}$. The proof proceeds similarly to case I. It is possible for the central bank to choose $p_{t+1}=1$ and then $q(1)$ which puts a lower bound on its payoff in period $t+1$, from (20):

$$
\begin{aligned}
& V_{t+1} \geq q_{t+1} f_{t+1}-\gamma\left[q_{t}-q^{*}\right]+\delta[V(1)-\beta]-\delta q(1) f_{t+1} \\
& V(1)-\beta-V_{t+1} \leq(1-\delta)(V(1)-\beta)-f_{t+1}\left(q_{t+1}-\delta q(1)\right)+\gamma\left[q_{t}-q^{*}\right]
\end{aligned}
$$

Since $p_{t}=f_{t}=1$ and $q\left(f_{t}\right)$ is nonincreasing in $f_{t}$, (22) requires,

$$
q(1)-q_{t+1} \leq V(1)-\beta-V_{t+1}
$$

Combining the two, 


$$
\begin{aligned}
& q(1)-q_{t+1} \leq(1-\delta)(V(1)-\beta)-f_{t+1}\left(q_{t+1}-\delta q(1)\right)+\gamma\left[q_{t}-q^{*}\right] \\
& (1-\delta)(V(1)-\beta) \geq q(1)-q_{t+1}+f_{t+1}\left(q_{t+1}-\delta q(1)\right)-\gamma\left[q_{t}-q^{*}\right]
\end{aligned}
$$

Since $p_{t}=f_{t}=1,(20)$ implies,

$$
V_{t}=q_{t}-\gamma\left[q_{t}-q^{*}\right]+\delta[V(1)-\beta]-\delta q(1)
$$

$p_{t-1}=f_{t-1}=0$ and (22) yield,

$$
0 \geq V(0)-\beta-V_{t}
$$

By proposition $1, V(1) \leq V(0) \Rightarrow V_{t} \geq V(1)-\beta$ so (B5) gives,

$$
\begin{array}{r}
V(1)-\beta \leq q_{t}-\gamma\left[q_{t}-q^{*}\right]+\delta[V(1)-\beta]-\delta q(1) \\
(1-\delta)(V(1)-\beta) \leq q_{t}-\gamma\left[q_{t}-q^{*}\right]-\delta q(1)
\end{array}
$$

Therefore (B4) implies,

$$
q(1)-q_{t+1}+f_{t+1}\left(q_{t+1}-\delta q(1)\right)-\gamma\left[q_{t}-q^{*}\right] \leq q_{t}-\gamma\left[q_{t}-q^{*}\right]-\delta q(1)
$$

Rearranging terms,

$$
\left[q_{t}-q(1)\right]-\gamma\left[q_{t}-q_{t+1}\right] \geq\left(1-f_{t+1}\right)\left(\delta q(1)-q_{t+1}\right)
$$

The L.H.S. is negative and the R.H.S. is positive by (B1). This contradiction implies that $p_{t-1}=0$ and $p_{t}=1$ is not possible for $t$ such that $q_{t} \geq q^{*}$, which proves (v). In addition, together case I and case II prove (iv).

\section{Appendix C: Proof of Proposition 3}

Define: $\sigma(V) \equiv(1-\delta)(V(0)-\beta)$ and $\varphi(V) \equiv(1-\delta)(V(1)-\beta-q(1))$. When no confusion results the argument $V$ will be omitted.

(i) If $q_{t+1} \geq q^{*}$ then $f_{t}=0 \forall t<\tau(0)$ by proposition 1 and, therefore, $p_{t}=0$ as previously shown. If $q_{t+1}<q^{*}$ then $f_{t+1}=0$ since $t+1<\tau(0)$. Since $p_{t+1}=1$ is possible, (20) implies,

$$
V_{t+1} \geq \gamma\left[q_{t+1}-q^{*}\right]+\delta(V(0)-\beta)
$$

so,

$$
\begin{aligned}
& V(0)-\beta-V_{t+1} \leq(1-\delta)(V(0)-\beta)-\gamma\left[q_{t+1}-q^{*}\right] \\
& V(0)-\beta-V_{t+1} \leq \sigma-\gamma\left[q_{t+1}-q^{*}\right]=q_{T^{*}+1}-\gamma\left[q_{t+1}-q^{*}\right]
\end{aligned}
$$

Since $T^{*}>t$

$$
V(0)-\beta-V_{t+1}<0
$$

so (22) implies $p_{t}=0$ and (i) is proven. 
(ii) $t \geq \bar{T} \Rightarrow q_{t}<q^{*}$.

By proposition 2, if $f_{t+1}>0$ then $t+1>\tau\left(f_{t+1}\right)$ and the definition of $\tau\left(f_{t+1}\right)$ imply,

$$
q_{t+1}+\alpha<\delta q\left(f_{t+1}\right)
$$

So for all $f_{t+1}$,

$$
f_{t+1}\left[q_{t+1}-\delta q\left(f_{t+1}\right)\right] \leq 0
$$

Claim 1: $\forall t \in \mathbb{R}_{+}, t>\bar{T} \Rightarrow p_{t}>0$.

Assume not: $t>\bar{T}$ and $p_{t}=0$. If $p_{t+1}>0$ then $p_{t+1}=1$ yields the same expected payoff:

$$
\begin{aligned}
& V_{t+1}=q_{t+1} f_{t+1}+\gamma\left[q_{t+1}-q^{*}\right]+\delta\left(V\left(f_{t+1}\right)-\beta-f_{t+1} q\left(f_{t+1}\right)\right) \\
& V_{t+1}=\gamma\left[q_{t+1}-q^{*}\right]+\delta\left(V\left(f_{t+1}\right)-\beta\right)+f_{t+1}\left(q_{t+1}-\delta q\left(f_{t+1}\right)\right) \\
& V(0)-\beta-V_{t+1}=(1-\delta)(V(0)-\beta)-\gamma\left[q_{t+1}-q^{*}\right]-f_{t+1}\left[q_{t+1}-\delta q\left(f_{t+1}\right)\right]
\end{aligned}
$$

and by $(\mathrm{C} 1)$

$$
V(0)-\beta-V_{t+1} \geq(1-\delta)(V(0)-\beta)-\gamma\left[q_{t+1}-q^{*}\right]
$$

Since $t \geq \bar{T}$,

$$
V(0)-\beta-V_{t+1} \geq \sigma-q_{t+1}>\varphi-q_{\bar{T}+1}>0
$$

Since $p_{t}=0 \Rightarrow f_{t}=0,(22)$ implies,

$$
V(0)-\beta-V_{t+1} \leq 0
$$

a contradiction, so if $p_{t+1}>0$ then $p_{t}>0$. If $p_{t+N}>0$ for any $N<\infty$, backward induction using the above implies that $p_{t}>0$.

If $p_{t+N}=0 \forall N \in \mathbb{N}$ then, by (21), $f_{t+N}=0 \forall N \in \mathbb{N}$. Therefore,

$$
V_{t+N}=\gamma\left[q_{t+N}-q^{*}\right]+\delta V_{t+N+1}
$$

and,

$$
V_{t+1}=\sum_{i=0}^{\infty} \delta^{i} \gamma\left[q_{t+i+1}-q^{*}\right]
$$

Since $q_{t+1+i}<q_{t+1} \forall i>0, V_{t+1}<\gamma\left[q_{t+1}-q^{*}\right] /(1-\delta)$. From the definition of $\sigma$ :

$$
(1-\delta)(V(0)-\beta)=\sigma>\varphi=\gamma\left[q-\bar{T}+1-q^{*}\right] \geq \gamma\left[q_{t+1}-q^{*}\right]
$$

so $V(0)-\beta>\gamma\left[q_{t+1}-q^{*}\right] /(1-\delta)$ therefore,

$$
\begin{aligned}
& V_{t+1}<V(0)-\beta \\
& V(0)-\beta-V_{t+1}>0
\end{aligned}
$$

Since $f_{t}=0$, (22) implies $p_{t}=1$, a contradiction and claim 1 is proven. 
Claim 2: $\forall t \in \mathbb{R}_{+}, t>\bar{T}$ and $p_{t} \in(0,1) \Rightarrow p_{t+1} \in(0,1)$.

Assume not: $t>\bar{T}, p_{t} \in(0,1)$ and $p_{t+1}=1$. From (20),

$$
V_{t+1}=q_{t+1} f_{t+1}+\gamma\left[q_{t+1}-q^{*}\right]+\delta\left(V\left(f_{t+1}\right)-\beta-f_{t+1} q\left(f_{t+1}\right)\right)
$$

If $t \leq \tau(0)$ then $f_{t}=0$ and $V\left(f_{t}\right) \geq V\left(f_{t+1}\right)$ so,

$$
\begin{aligned}
& V_{t+1} \leq q_{t+1} f_{t+1}+\gamma\left[q_{t+1}-q^{*}\right]+\delta\left(V(0)-\beta-f_{t+1} q\left(f_{t+1}\right)\right) \\
& V(0)-\beta-V_{t+1} \geq(1-\delta)(V(0)-\beta)-f_{t+1}\left(q_{t+1}-\delta q\left(f_{t+1}\right)\right)-\gamma\left[q_{t+1}-q^{*}\right]
\end{aligned}
$$

and, by (C1),

$$
V(0)-\beta-V_{t+1} \geq \sigma-\gamma\left[q_{t+1}-q^{*}\right]
$$

$t>\bar{T} \Rightarrow \sigma<\gamma\left[q_{t+1}-q^{*}\right]$ so,

$$
V(0)-\beta-V_{t+1}>0
$$

This is inconsistent with $p_{t} \in(0,1)$, by (22), so claim 2 holds for $t \leq \tau(0)$.

If $t>\tau(0)$ then either $t \in(\tau(0), \tau(1)]$ or $t>\tau(1)$. In the first instance the definition of $\tau(\cdot) \Rightarrow p_{t+1}=1$ leads to $f_{t+1}>0$ and $f_{t+1}>f_{t}$. In the second instance $p_{t+1}=1$ leads to $f_{t+1}=1$ and, therefore, to $f_{t+1} \geq f_{t}$. In either case $f_{t+1} \geq f_{t}$ and, since $p_{t} \in(0,1),(22)$ yields,

$$
\begin{aligned}
& V\left(f_{t}\right)-\beta-V_{t+1}=f_{t}\left(q\left(f_{t}\right)-q_{t+1}\right) \\
& V\left(f_{t}\right)-f_{t} q\left(f_{t}\right)=\beta+V_{t+1}-f_{t} q_{t+1}
\end{aligned}
$$

and from the optimality of $q\left(f_{t}\right)$,

$$
\begin{aligned}
& V\left(f_{t+1}\right)-f_{t} q\left(f_{t+1}\right) \leq \beta+V_{t+1}-f_{t} q_{t+1} \\
& V\left(f_{t+1}\right)-\beta-V_{t+1} \leq f_{t}\left(q\left(f_{t+1}\right)-q_{t+1}\right) \\
& V\left(f_{t+1}\right)-\beta-V_{t+1} \leq f_{t+1}\left(q\left(f_{t+1}\right)-q_{t+1}\right)
\end{aligned}
$$

Since $p_{t+1}=1,(20)$ gives,

$$
\begin{aligned}
& V_{t+1}=q_{t+1} f_{t+1}+\gamma\left[q_{t+1}-q^{*}\right]+\delta\left(V\left(f_{t+1}\right)-\beta-f_{t+1} q\left(f_{t+1}\right)\right) \\
& V\left(f_{t+1}\right)-\beta-V_{t+1}=(1-\delta)\left(V\left(f_{t+1}\right)-\beta\right)-f_{t+1}\left(q_{t+1}-\delta q\left(f_{t+1}\right)\right)-\gamma\left[q_{t+1}-q^{*}\right]
\end{aligned}
$$

And (C2) implies,

$$
f_{t+1}\left(q\left(f_{t+1}\right)-q_{t+1}\right) \geq(1-\delta)\left(V\left(f_{t+1}\right)-\beta\right)-f_{t}\left(q_{t+1}-\delta q\left(f_{t+1}\right)\right)-\gamma\left[q_{t+1}-q^{*}\right]
$$

and, from (C1),

$$
\begin{aligned}
& f_{t+1}\left(q\left(f_{t+1}\right)-\delta q\left(f_{t+1}\right)\right) \geq(1-\delta)\left(V\left(f_{t+1}\right)-\beta\right)-\gamma\left[q_{t+1}-q^{*}\right] \\
& \left(q\left(f_{t+1}\right)-\delta q\left(f_{t+1}\right)\right) \geq(1-\delta)\left(V\left(f_{t+1}\right)-\beta-f_{t+1} q_{t+1}\right) \\
& \gamma\left[q_{t+1}-q^{*}\right] \geq(1-\delta)\left(V\left(f_{t+1}\right)-\beta-q\left(f_{t+1}\right)\right) \geq \varphi=q_{\bar{T}+1}
\end{aligned}
$$

Which contradicts $t>\bar{T}$ so claim 2 is proven. 
From the above, to prove the first part of (ii) by contradiction it is only necessary to show that $p_{t} \in(0,1)$ is impossible for $t>\bar{T}$. By iteration of claim $2, p_{t} \in(0,1) \Rightarrow p_{t+N} \in(0,1)$. Either $\exists N \in \mathbb{N}$ where $f_{t+N}<f_{t+N+1}$ or $f_{t+N} \geq f_{N+1} \forall N \in \mathbb{N}$. Since $f_{t+N+1} \geq 0$ this second case implies that $\exists N \in \mathbb{N}$ such that

$$
f_{t+N}-f_{t+N+1}<\varepsilon
$$

for any $\varepsilon$, however small. Taking such an $N, p_{t+N} \in(0,1)$ implies,

$$
V\left(f_{t+N}\right)-\beta-V_{t+1+N}=f_{t+N}\left(q\left(f_{t+N}\right)-q_{t+1+N}\right)
$$

$p_{t+1+N} \in(0,1)$ implies that $p_{t+1+N}=1$ yields the same expected payoff,

$$
\begin{aligned}
V_{t+1+N}= & q_{t+1+N} f_{t+1+N}+\gamma\left[q_{t+1+N}-q^{*}\right]+\delta\left(V\left(f_{t+1+N}\right)\right. \\
& \left.-\beta-f_{t+1+N} q\left(f_{t+1+N}\right)\right)
\end{aligned}
$$

Combining the two,

$$
\begin{aligned}
V\left(f_{t+N}\right)-\beta+f_{t+N}\left(q_{t+1+N}-q\left(f_{t+N}\right)\right)= & q_{t+1+N} f_{t+1+N}+\gamma\left[q_{t+1+N}-q^{*}\right] \\
& +\delta\left(V\left(f_{t+1+N}\right)-\beta-f_{t+1+N} q\left(f_{t+1+N}\right)\right) \\
{\left[V\left(f_{t+N}\right)-\beta\right]-\left[V\left(f_{t+1+N}\right)-\beta\right]=} & f_{t+1+N}\left[q_{t+1+N}-\delta q\left(f_{t+1+N}\right)\right] \\
& -f_{t+N}\left[q_{t+1+N}-q\left(f_{t+N}\right)\right]+\gamma\left[q_{t+1+N}-q^{*}\right]
\end{aligned}
$$

which can be rewritten as:

$$
\begin{gathered}
(1-\delta)\left[V\left(f_{t+N}\right)-\beta-f_{t+N} q\left(f_{t+N}\right)\right]-\gamma\left[q_{t+1}-q^{*}\right]+\delta\left[V\left(f_{t+N}\right)-\beta-f_{t+N} q\left(f_{t+N}\right)\right] \\
-\delta\left[V\left(f_{t+1+N}\right)-\beta-f_{t+1+N} q\left(f_{t+N}+1\right)\right]=q_{t+1+N}\left[f_{t+1+N}-f_{t+N}\right] \approx 0
\end{gathered}
$$

By the optimality of $q\left(f_{t+N}\right)$,

$$
\begin{aligned}
& (1-\delta)[V(1)-\beta-q(1)]-\gamma\left[q_{t+1}-q^{*}\right] \\
& \quad+\delta\left[V\left(f_{t+1+N}\right)-\beta-f_{t+N} q\left(f_{t+1+N}\right)\right]-\delta\left[V\left(f_{t+1+N}\right)-\beta-f_{t+1+N} q\left(f_{t+N}+1\right)\right] \leq 0
\end{aligned}
$$

which reduces to,

$$
(1-\delta)[V(1)-\beta-q(1)]-\gamma\left[q_{t+1}-q^{*}\right] \leq \delta q\left(f_{t+N}+1\right)\left[f_{t+1+N}-f_{t+N}\right] \approx 0
$$

a contradiction since $t>\bar{T}$ which implies that $\exists N \in \mathbb{N}$ s.t. $f_{t+N}<f_{t+N+1} \Rightarrow$ $t+N+1>\tau(0)$ by proposition 2 .

Considering such an $N,(\mathrm{C} 3)$ yields,

$$
\begin{aligned}
& {\left[V\left(f_{t+1+N}\right)-f_{t+1+N} q\left(f_{t+1+N}\right)\right]-\beta-V_{t+1+N}=} \\
& \quad(1-\delta)\left[V\left(f_{t+1+N}\right)-\beta-f_{t+1+N} q\left(f_{t+1+N}\right)\right]-\gamma\left[q_{t+1+N}-q^{*}\right]-f_{t+1+N} q_{t+1+N}
\end{aligned}
$$

From the optimality of $f_{t+1+N}, V\left(f_{t+1+N}\right)-f_{t+1+N} q\left(f_{t+1+N}\right) \geq V(1)-q(1)$ and $f_{t+1+N}>f_{t+N}$, 


$$
\begin{aligned}
& {\left[V\left(f_{t+1}\right)-f_{t+1} q\left(f_{t+1}\right)\right]-\beta-V_{t+1+N} \geq(1-\delta)[V(1)-\beta-q(1)]} \\
& \quad-\gamma\left[q_{t+1+N}-q^{*}\right]-f_{t+1+N} q_{t+1+N} \\
& V\left(f_{t+1}\right)-\beta-V_{t+1} \geq(1-\delta)[V(1)-\beta-q(1)] \\
& \quad-\gamma\left[q_{t++N}-q^{*}\right]+f_{t+N}\left[q\left(f_{t+1+N}\right)-q_{t+1+N}\right]
\end{aligned}
$$

since $t>\bar{T} \Rightarrow \varphi>\gamma\left[q_{t+1+N}-q^{*}\right]$,

$$
V\left(f_{t+N}\right)-\beta-V_{t+1+N}>f_{t+N}\left[q\left(f_{t+N}\right)-q_{t+1+N}\right]
$$

So (22) guarantees that $p_{t+N}=1$ so iteration of claim 2 implies that $p_{t} \notin(0,1)$ and the first part of (ii) is proven.

For the second part of (ii), if $t+1 \leq \tau(0)$, then $f_{t+1}=0$, from the definition of $\tau(0)$, and $p_{t}=1$ from the definition of $\bar{T}$. If $t+1 \geq \tau(0)$ then, $0<t=\bar{T} \leq$ $\tau(0) \Rightarrow p_{t+1}=1$, from the first part of (ii), and $f_{t+1}>0$, so (20) yields,

$$
V_{t+1}=q_{t+1} f_{t+1}+\gamma\left[q_{t+1}-q^{*}\right]+\delta\left[V\left(f_{t+1}\right)-\beta-f_{t+1} q\left(f_{t+1}\right)\right]
$$

By $V(0) \geq V\left(f_{t+1}\right)$ and since $f_{t+1}>0$ implies that $\delta q\left(f_{t+1}\right)>q_{t+1}$,

$$
\begin{aligned}
& V_{t+1}<\delta[V(0)-\beta]+\gamma\left[q_{t+1}-q^{*}\right] \\
& V(0)-\beta-V_{t+1}>\delta[V(0)-\beta]-q_{t+1}=\sigma-q_{t+1}>\varphi-q_{t+1}
\end{aligned}
$$

Since $t=\bar{T}, \varphi=q_{t+1}$ so $V(0)-\beta-V_{t+1}>0$. By the definition of $\tau(0)$, $t \leq \tau(0) \Rightarrow f_{t}=0$ so (22) implies that $p_{t}=1$, and (ii) is proven.

(iii) If $p_{t}=1$ then $f_{t}=1$ since $t>\tau(1) . t=\bar{T}>\tau(1) \Rightarrow p_{t+1}=1$, by (ii), and $f_{t+1}=1$, by the definition of $\tau(1)$, therefore (20) implies,

$$
\begin{aligned}
& V_{t+1}=q_{t+1}+\delta[V(1)-\beta-q(1)]+\gamma\left[q_{t+1}-q^{*}\right] \\
& V(1)-\beta-V_{t+1}=(1-\delta)[V(1)-\beta]-\gamma\left[q_{t+1}-q^{*}\right]-q_{t+1}+\delta q(1) \\
& V(1)-\beta-V_{t+1}=(1-\delta)[V(1)-\beta-q(1)]-\gamma\left[q_{t+1}-q^{*}\right]+q(1)-q_{t+1}
\end{aligned}
$$

Since $t=\bar{T} \Rightarrow \varphi=q_{t+1}$,

$$
V(1)-\beta-V_{t+1}=\left[q(1)-q_{t+1}\right]
$$

So if $f_{t}=1$ the central bank is indifferent between any probability of devaluation. However, if $f_{t}<1$,

$$
\begin{aligned}
& V(1)-\beta-V_{t+1}>f_{t}\left[q(1)-q_{t+1}\right] \\
& {\left[V(1)-f_{t} q(1)\right]-\beta-V_{t+1}>-f_{t} q_{t+1}}
\end{aligned}
$$

and by the optimality of $q\left(f_{t}\right)$,

$$
\begin{aligned}
& {\left[V\left(f_{t}\right)-f_{t} q\left(f_{t}\right)\right]-\beta-V_{t+1}>-f_{t} q_{t+1}} \\
& V\left(f_{t}\right)-\beta-V_{t+1}>f_{t}\left[q\left(f_{t}\right)-q_{t+1}\right]
\end{aligned}
$$

Therefore, $f_{t}<1 \Rightarrow p_{t}=1$. But, since $t>\tau(1)$ this implies $f_{t}=1$, so $f_{t}=1$ is required in equilibrium. 
Therefore (21) gives,

$$
q_{t}+\alpha \leq \delta\left[p_{t} q(1)+\left(1-p_{t}\right) q_{t+1}\right]
$$

Solving for $p_{t}$,

$$
p_{t} \geq \frac{q_{t}-\delta q_{t+1}+\alpha}{\delta\left[q(1)-q_{t+1}\right]}
$$

which completes the proof of (iii).

\section{Appendix D: Proof of Proposition 4}

(i) By (27) $F_{t}$ satisfies,

$$
F_{t}\left[q\left(F_{t}\right)-q_{t+1}\right]=V\left(F_{t}\right)-\beta-V_{t+1}
$$

and differentiation with respect to $F_{t}$ and $t$ yields,

$$
\left\{\left(q\left(F_{t}\right)-q_{t+1}\right)+F_{t} \frac{\partial q\left(F_{t}\right)}{\partial F_{t}}-\frac{\partial V\left(F_{t}\right)}{\partial F_{t}}\right\} d F_{t}=\left\{F_{t} \frac{\partial q_{t+1}}{\partial t}-\frac{\partial V_{t+1}}{\partial t}\right\} d t
$$

The L.H.S. is positive by proposition 1, as is the R.H.S. since,

$$
\frac{\partial V_{t+1}}{\partial t}=\left[F_{t+1}+1\right] \frac{\partial q_{t+1}}{\partial t}<F_{t} \frac{\partial q_{t+1}}{\partial t}
$$

which proves (i).

(ii) By (21) $P_{t}$ satisfies,

$$
q_{t}+\alpha=\delta P_{t} q\left(f_{t}\right)+\delta\left(1-P_{t}\right) q_{t+1}
$$

and differentiation with respect to $P_{t}$ and $t$ yields,

$$
\left\{\frac{\partial q_{t}}{\partial t}-\delta\left(1-P_{t}\right) \frac{\partial q_{t+1}}{\partial t}-\delta P_{t} \frac{\partial q\left(f_{t}\right)}{\partial f_{t}} \frac{\partial f_{t}}{\partial t}\right\} d t=\left\{q\left(f_{t}\right)-q_{t+1}\right\} d P_{t}
$$

The R.H.S. is positive. The L.H.S. is negative by (i), proposition 1 and the fact that,

$$
\left[\left(\partial q_{t} / \partial t\right)-\left(\partial q_{t+1} / \partial t\right)\right]=\left[q_{t+1}-q_{t}\right] \ln (\theta)<0
$$

which proves the first part of (ii). As $t \rightarrow \infty, q_{t}$ and $q_{t+1} \rightarrow 0$ so (26) and (33) quickly yield the second part of (ii). 


\section{Appendix E: Proof of Proposition 5}

(i) and (ii) Evaluate (29) at $t \geq T^{*} \cdot q_{t+1}<q^{*}$ and $V\left(f_{t+1}\right) \leq V\left(f_{t}\right)$ so,

$$
\begin{aligned}
& f_{t} \geq \frac{(1-\delta)\left(V\left(f_{t+1}\right)-\beta\right)-\gamma\left[q_{t+1}-q^{*}\right]}{q\left(f_{t}\right)-q_{t+1}}+\frac{\left[\delta q\left(f_{t+1}\right)-q_{t+1}\right]}{q\left(f_{t}\right)-q_{t+1}} \cdot f_{t+1} \\
& f_{t} \geq \frac{(1-\delta)(V(1)-\beta-q(1))-\gamma\left[q_{t+1}-q^{*}\right]}{q\left(f_{t}\right)-q_{t+1}}+\frac{\left[\delta q\left(f_{t+1}\right)-q_{t+1}\right]}{q\left(f_{t}\right)-q_{t+1}} \cdot f_{t+1}
\end{aligned}
$$

Since at $t \geq T^{*}, \varphi \geq \gamma\left[q_{t+1}-q^{*}\right]$,

$$
f_{t} \geq \frac{\left[\delta q\left(f_{t+1}\right)-q_{t+1}\right]}{q\left(f_{t}\right)-q_{t+1}} \cdot f_{t+1}
$$

So, if $t>\tau(0)-1$ and $t \geq T^{*}$ then $f_{t+1}>0 \Rightarrow f_{t}>0$ which implies $\underline{T}<T^{*}$ if $T^{*}>\tau(0)-1$. If $T^{*} \leq \tau(0)-1$ then, by definition, $\underline{T}=T^{*}$.

(iii) Define: $\hat{q} \equiv \max \left\{q_{\underline{T}}, q^{*}\right\}, \forall t$ such that $q_{t}>\hat{q}, f_{t}=p_{t}=0$. Therefore, considering arbitrarily short time intervals, $\forall q>\hat{q}$, the choice of $q$ is equivalent to the choice of $k \in \mathbb{R}$ where $q \equiv q_{0} \theta^{k}$ and $V(q)$ is equivalent to $V(k)$ :

$$
V(k)=\sum_{i=0}^{k} \delta^{i}\left[q^{*}-\hat{q} \theta^{k-i}\right]+\delta^{k} Z
$$

where,

$$
\begin{array}{ll}
Z \equiv \hat{q} f(\hat{q})+\delta(V(q(f(\hat{q}))-\beta-f(\hat{q}) q(f(\hat{q})) & \text { if } f(\hat{q})>0 \\
Z \equiv \delta V(\hat{q} / \theta) & \text { if } f(\hat{q})=0
\end{array}
$$

since $f(\hat{q})>0 \Rightarrow p>0$ and, at $q=\hat{q}, p=1$ is not possible by proposition 2 (in the previous period $\mathrm{p}=0$ ).

Defining,

$$
\begin{aligned}
& Y(k)=\sum_{i=0}^{k} \delta^{i}\left[q^{*}-\hat{q} \theta^{k-i}\right] \\
& Y(k+1)=\delta Y(k)+\left[q^{*}-\hat{q} \theta^{k+1}\right]
\end{aligned}
$$

Therefore,

$$
\partial Y(k) / \partial k \approx Y(k+1)-Y(k)=-(1-\delta) Y(k)+\left[q^{*}-\hat{q} \theta^{k+1}\right]
$$

so, 


$$
\begin{gathered}
\partial V(k) / \partial k \approx-(1-\delta) Y(k)+\left[q^{*}-\hat{q} \theta^{k+1}\right]+\ln (\delta) \delta^{k} Z \\
\partial V(k) / \partial k \approx-(1-\delta) q^{*} \sum_{i=0}^{k} \delta^{i}+(1-\delta) \hat{q} \theta^{k} \sum_{i=0}^{k}(\delta / \theta)^{i}+q^{*} \\
-\hat{q} \theta^{k+1}+\ln (\delta) \delta^{k} Z \\
\partial V(k) / \partial k \lesssim-(1-\delta) q^{*} \sum_{i=0}^{k} \delta^{i}+(1-\delta) \hat{q} \theta^{k+1} /(\theta-\delta)+q^{*} \\
-\hat{q} \theta^{k+1}+\ln (\delta) \delta^{k} Z \\
\lim _{k \rightarrow \infty}[\partial V(k) / \partial k] \lesssim-(1-\delta) q^{*} /(1-\delta) \\
-\hat{q}[1-(1-\delta) /(\theta-\delta)] \lim _{k \rightarrow \infty}\left[\theta^{k+1}\right]+q^{*} \\
\lim _{k \rightarrow \infty}[\partial V(k) / \partial k] \lesssim-\infty
\end{gathered}
$$

Which implies that in equilibrium $q(0)<\infty \Rightarrow q_{0}<\infty$.

\section{References}

Agénor, P. R., Bhandari J., Robert Flood R.: Speculative attacks and models of balance-of-payments crises. International Monetary Fund Staff Papers 39, 357-394 (1992)

Andersen, T.: Shocks and the viability of a fixed exchange rate commitment. CEPR Discussion Paper \# 969 (1994)

Bénabou, R.: Optimal price dynamics and speculation with a storable good. Econometrica 57, 41-80 (1989)

Blackburn, K., Sola, M.: Speculative currency attacks and balance-of-payments crises. Journal of Economic Surveys 7, 119-144 (1993)

Blackwell, D.: Discounted dynamic programming. Annals of Mathematical Statistics 36, 226-235 (1965)

Blanco, H., Garber, P.: Recurrent devaluation and speculative attacks on the Mexican Peso. Journal of Political Economy 94, 148-166 (1986)

Cole, H., Kehoe, T.: A self-fulfilling model of Mexico's 1994-1995 debt crisis. Journal of International Economics 41, 309-330 (1996a)

Cole, H., Kehoe, T.: Self-fulfilling debt crises. Federal Reserve Bank of Minneapolis Research Department Staff Report \# 211 (1996b)

Collins, S.: The timing of exchange rate adjustment in developing countries. Unpublished (1995)

Davies, G., Vines, D.: Equilibrium currency crises: are multiple equilibria self-fulfilling or history dependent? CEPR Discussion Paper \# 1239 (1995)

Eichengreen, B., Rose, A., Wyplosz, C.: Exchange market mayhem: the antecedents and aftermath of speculative attacks. Economic Policy 21, 251-312 (1995)

Flood, R., Garber, P.: Collapsing exchange-rate regimes: some linear examples. Journal of International Economics 17, 1-13 (1984)

Flood, R., Marion, N.: The size and timing of devaluations in capital-controlled economies. Journal of Development Economics 54(1), 123-147 (1997a)

Flood, R., Marion, N.: Perspectives on the recent currency crisis literature. Unpublished (1997b)

Gertner, R.: Dynamic duopoly with price inertia. Unpublished (1985)

Harsanyi, J.: Games with randomly disturbed payoffs: a new rational for mixed-strategy equilibrium points. International Journal of Game Theory 2, 1-23 (1973)

Klein, M., Marion, N.: Explaining the duration of exchange-rate pegs. Journal of Development Economics 54, 387-404 (1997)

Krugman, P.: A model of balance-of-payments crises. Journal of Money, Credit, and Banking 11, 311-325 (1979) 
Maskin, E., Tirole, J.: A theory of dynamic oligopoly. III: Cournot competition: European Economic Review 31, 947-968 (1987)

Maskin, E., Tirole, J.: A theory of dynamic oligopoly. I: Overview and quantity competition with large fixed costs. Econometrica 56, 549-569 (1988a)

Maskin, E., Tirole, J.: A theory of dynamic oligopoly. II: Price competition, kinked demand curves, and edge worth cycles. Econometrica 56, 571-599 (1988b)

Morris, S., Shin, H.: Unique equilibrium in a model of self-fulfilling currency attacks. American Economic Review 88, 587-597 (1998)

Obstfeld, M.: Rational and self-fulfilling balance-of-payments crises. American Economic Review 76, 72-81 (1986)

Obstfeld, M.: The logic of currency crises. NBER Working Paper \# 4640 (1994)

Obstfeld, M.: Models of currency crises with self-fulfilling features. CEPR Discussion Paper \# 1315 (1996)

Ozkan, G., Sutherland, A.: A model of the ERM crisis. CEPR Discussion Paper \# 879 (1994)

Ozkan, G., Sutherland, A.: Policy measures to avoid a currency crisis. Economic Journal 105, 510 519 (1995)

Ozkan, G., Sutherland, A.: A currency crisis model with an optimising policymaker. Journal of International Economics 44, 339-364 (1998)

Pastine, I.: Speculation and the decision to abandon a fixed exchange rate regime. Unpublished (1998)

Penati, A., Pennacchi, G.: Optimal portfolio choice and the collapse of a fixed-exchange rate regime. Journal of International Economics 27, 1-24 (1989)

Salant, S., Henderson, D.: Market anticipations of government policies and the price of gold. Journal of Political Economy 86, 627-648 (1978)

Sheshinski, E., Weiss, Y.: Inflation and costs of price adjustments. Review of Economic Studies 44, 287-303 (1977)

Velasco, A.: When are fixed exchange rates really fixed? Journal of Development Economics 54, 5-25 (1997) 